\title{
Financial modelling, risk management of energy instruments and the role of cryptocurrencies
}

\author{
Toan Luu Duc Huynh ${ }^{1,2}$ - Muhammad Shahbaz ${ }^{3,4} \cdot$ Muhammad Ali Nasir $^{1,5}$. \\ Subhan Ullah ${ }^{6}$
}

Published online: 2 July 2020

(c) The Author(s) 2021

\begin{abstract}
This paper empirically investigates whether cryptocurrencies might have a useful role in financial modelling and risk management in the energy markets. To do so, the causal relationship between movements on the energy markets (specifically the price of crude oil) and the value of cryptocurrencies is analysed by drawing on daily data from April 2013 to April 2019. We find that shocks to the US and European crude oil indices are strongly connected to the movements of most cryptocurrencies. Applying a non-parametric statistic, Transferring Entropy (an econophysics technique measuring information flow), we find that some cryptocurrencies (XEM, DOGE, VTC, XLM, USDT, XRP) can be used for hedging and portfolio diversification. Furthermore, the results reveal that the European crude oil index is a source of shocks on the cryptocurrency market while the US oil index appears to be a receiver of shocks.
\end{abstract}

Keywords Energy markets · Risk management · Crude oil · Cryptocurrency · Transfer entropy $\cdot$ Financial instruments

JEL Classification $\mathrm{O} 31 \cdot \mathrm{G} 18 \cdot \mathrm{O} 32 \cdot \mathrm{O} 33$

Toan Luu Duc Huynh

toanhld@ueh.edu.vn

1 School of Banking, University of Economics Ho Chi Minh City, Ho Chi Minh City, Vietnam

2 Chair of Behavioral Finance, WHU - Otto Beisheim School of Management, Burgplatz 2, 56179 Vallendar, Germany

3 School of Management and Economics, Beijing Institute of Technology, Beijing, China

4 Department of Land Economy, University of Cambridge, Cambridge, UK

5 Leeds Business School, Leeds Beckett University, Leeds, UK

6 Division of Accounting, Nottingham University Business School, University of Nottingham, Nottingham, UK 


\section{Introduction}

Climate change is one of the most crucial and hence widely debated issues over the last decade. The need to tackle it at the global scale provides a rationale to explore the role of energy and environmental instruments in reducing carbon emissions. The financial sector, with its crucial role in the economy and society, should play its part (Shahbaz et al. 2018; Nasir et al. 2019).

The oil price always conveys a large amount of information to researchers, investors and policymakers. Empirical research (Balke et al. 2002; Hamilton 2003; Barsky and Kilian 2004; Chen and Chen 2007; Kilian and Park 2009; Elder and Serletis 2010; Jo 2014; Degiannakis and Filis 2017) has confirmed that the uncertain movement of oil prices can have different effects on different economies and financial assets. It is highly likely that major economic indicators strongly rely on the crude oil market, which reflects all 'goodor-bad' information relating to global geopolitics. For example, the West Texas Intermediate (WTI) index peaked at around US\$75 per barrel at the beginning of October 2018 and then fell to around US\$40 per barrel at the beginning of January 2019. Keynes's (1923) seminal work in this area encourages researchers to study the stochastic dynamics in oil and commodity markets. Although there is plenty of theoretical and empirical research on oil price modelling to capture the uncertain movements in the oil price, oil prices movements still attract much scholarly attention, with more sophisticated empirical methods. As of July 2018, the cryptocurrency market accounted for over US\$300 billion worth of market capitalization, with nearly 2000 'coins' trading.

Crude oil shipments were worth $\$ 486.3$ billion (from World's Top Exports) whereas the market capitalization for cryptocurrencies was worth $\$ 171$ billion (from coinmarketcap. com, 26th April 2019). Given such a high level of investment in these two assets, we are interested in examining whether there are links between the crude oil and the cryptocurrency markets.

There are a number of other reasons to examine the causal relationship between crude oil indices and movements on cryptocurrency markets. First, recently, many countries have shown interest in issuing their own coins for oil trading, including Venezuela, Russia, and the United States. Nicolás Maduro, Venezuela's President, stated: "In 2019, we have a schedule for [oil] to be sold for Petro (the name of cryptocurrency backed by crude oil prices) and in this way continue to free us from a currency that the elite of Washington uses". ${ }^{1}$ Taking inspiration from the mechanisms of current cryptocurrency platforms (Bitcoin, Ethereum, Litecoin, etc.) many countries around the world are likely to introduce their own cryptocurrencies to trade oil and other commodities. Second, understanding of the co-movements is necessary in establishing the initial valuation of a new coin. Valuation models provide a preliminary pricing mechanism for those interested in issuing new cryptocurrencies. Third, the phenomenal growth of the cryptocurrencies market has been attracting the attention of both individual and institutional investors, as cryptocurrencies provide an alternative investment platform for the hedging and diversification of investors' portfolios. We believe the next decade will see substantial research outputs on the linkage between crude oil and cryptocurrencies in different markets around the globe.

Several governments, including those of Russia, Iran and Venezuela, have already taken measures to regulate the oil markets by issuing their own coins. For instance, Igor Yusufov,

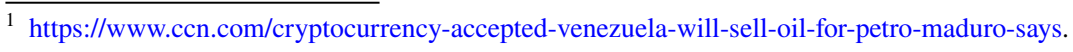


former energy minister of Russia, announced that his country is in the final stages of issuing a cryptocurrency based on the fundamental of the petrodollar. Every cryptocurrency platform (Bitcoin, Ethereum, Litecoin, etc.) needs to possess the key characteristics of any strong fundamental coin. It is anticipated that the application of cryptocurrencies in trading crude oil will gradually become a normal method of payment for many governments and will be an enormously useful means to control their commodity prices. Many countries in Eastern Asia are currently facing conflicts, trade restrictions and economic sanctions from the United States, and these states are likely to adopt alternative payment platforms using cryptocurrencies by introducing their own petrol-coins. ${ }^{2}$ Hence, understanding the dynamic relationship between a coin and crude oil is one of the initial steps in assessing the possibility of launching an oil trading currency. The rapid growth of the cryptocurrency market is an emerging area of research in the field of energy economics and finance, and has recently attracted much scholarly attention. Cryptocurrency is not only a trending financial investment but is also considered to be 'The decentralized transaction system empire' (Ammous 2018). The bitcoin standard: the decentralized alternative to central banking. John Wiley \& Sons.Bitcoin was first introduced in 2009 with a market price of a few cents. Its price had climbed to over $\$ 14,000$ by December 2017. More recently, the market capitalization of Bitcoin has surpassed US\$200 billion, while around six million users have virtual wallets and nearly one billion confirmed transactions occur every day (Hileman and Rauchs 2017).

Investors who choose cryptocurrencies as alternative investment platforms are likely to consider the linkage between these two markets. Why? To answer this, we need to empirically establish the nature of directional causality to understand how crude oil prices influence cryptocurrencies and vice versa. Investors need to ascertain the determinants of this causal relationship to make wise investment decisions. A deep understanding of this connection between crude oil and the cryptocurrency market is of great importance in several ways. First, oil and cryptocurrencies are not homogenous assets and, currently, there are several kinds of internationally traded crude oils as well as a range of cryptocurrencies. The different varieties of oil commodities and cryptocurrencies offer a good opportunity to investigate the underlying relationship between these complex payment instruments and crude oil prices. Second, the movement of oil prices depends on macroscopic economic factors, which leads to the market experiencing many external exogenous shocks. Although the cryptocurrency market is a fairly new addition to the global financial system, and is relatively independent of macroeconomic factors in these early stages, over time prices of cryptocurrencies are likely to become increasingly connected with the global energy market. This implies that investors will tend to use cryptocurrencies to hedge against volatility in the oil markets. Thus, the investigation of this causal relationship will guide investments in financial instruments. Third, Laherrere (2006) showed the role of benchmark crude oil indices, such as Brent for Europe and WTI for the American market. These indices convey many prospective indicators used for economic and financial forecasting. While the rapid expansion of blockchain and cryptocurrency can be practically applied in oil trading, it is possible to examine the connections among these highly volatile assets. Fourth, the cryptocurrency market has similar features to the oil market, such as market risk (Koutmos 2019), the network correlation with the other conventional markets (Giudici and Polinesi 2019),

${ }_{2}^{2}$ Petrol-coins refers to the kind of cryptocurrency which is called 'Petrol' backed by crude oil. 
technical trading and returns (Hudson and Urquhart 2019). Therefore, it is necessary to consider the link between cryptocurrencies and energy markets.

Finally, this study adds to the existing and growing body of energy-finance literature relating to cryptocurrencies. The theoretical and empirical literature on cryptocurrencies has developed in various areas. A few studies have focused on the regulatory aspect of Bitcoin. For instance, Stokes (2012), Raymaekers (2015), Böhme et al. (2015), Vandezande (2017), Pieters and Vivanco (2017) evaluated the regulatory framework of Bitcoin as a financial asset being traded on real markets. Other researchers discuss whether Bitcoin is likely to be treated as a speculative asset (Baur et al. 2018; Blau 2017; Bouri et al. 2017; Dyhrberg 2016; Glaser et al. 2014; Yermack 2015). Their results indicate that Bitcoin is a suitable investment for diversification, and has the potential to be used as a safe haven for hedging purposes. Bouri et al. (2017) further examine whether Bitcoin can be considered a safe haven, hedge or a diversifier against volatility in a commodity index. Their findings indicate that Bitcoin is a safe haven and a strong hedge for energy commodities. Recent studies have also measured the relationship between Bitcoin volatility and its returns in the comparative international context (Balcilar et al. 2017; Katsiampa 2017; Peng et al. 2018). In addition, a few recent studies have examined the contagion risk and spillover effects among cryptocurrencies (for example, Ciaian and Rajcaniova 2018; Corbet et al. 2018; Symitsi and Chalvatzis 2018; Huynh et al. 2018; Huynh 2019). Recently, researchers have also raised concerns about the efficiency of the cryptocurrency market (Urquhart 2016; Nadarajah and Chu 2017; Bariviera 2017; Sensoy 2019). However, few studies have investigated the influence of cryptocurrencies on crude oil markets or vice versa, and this study attempts to fill this gap in the energy-finance literature.

In this context, the aim of this paper is to examine information spillovers between a commodity asset (specifically oil) and a digital cryptocurrency (e.g., Bitcoin). Our data cover $80 \%$ of the market capitalization of cryptocurrency alongside two main oil indexes (US crude oil and European crude oil). With regard to methodology, we use an entropy approach to capture the direction of spillovers within the information network, from a static perspective. In contrast, previous studies have focused on lagged terms, for example within a Vector-Auto-Regression model. We employ different indicators to identify the importance of each cryptocurrency being studied within the global energy market.

The remainder of this paper is organized as follows. Section 2 reviews the literature and highlights our contribution. The methodology and data sources are explained in Sect. 3. Section 4 presents the preliminary data analytics and empirical findings. Finally, Sect. 5 concludes the paper with policy implications.

\section{Literature review}

Regulatory bodies and investors, in particular, are concerned about excessive volatility and abnormal returns in the cryptocurrency market. Higher abnormal returns in these markets make investment in cryptocurrency more appealing to the investor community. Recent research on cryptocurrencies shows that investors can achieve substantial returns by diversifying across different cryptocurrencies (Liu 2018).

A few studies have attempted to test the assumptions of market efficiency for cryptocurrencies. Examining the seasonality effect for cryptocurrencies, Kaiser (2018) could not observe robust and consistent calendar effects on cryptocurrency returns. He nevertheless found that the volatility and spreads, as well as trading volume, were generally lower on 
weekends and in January. Behavioural finance researchers have also raised concerns about the volatility of the cryptocurrency market. Investigating the widespread noise and sentiment-driven trading in the cryptocurrency market, Kallinterakis (2019) found a significant herding effect. He argued that the extreme noise and volatility in these markets had a destabilizing effect on associated financial markets.

In the energy research literature, Krugman's (1983) seminal work provides a solid foundation for understanding the economic perspectives on and implications of oil prices. He argued that volatility in oil prices can cause a reciprocal change in the foreign exchange markets in terms of multilateral relationships. A number of other studies have also contributed to the literature on oil prices and currencies. For instance, Lizardo and Mollick (2010) asserted that there is a significant relationship between positive oil shocks and subsequent depreciation of the US dollar. This result is similar to the work of Adler and Sosa (2011), Aloui et al. (2013), Reboredo (2012), Reboredo et al. (2014), Coudert and Mignon (2016), who all reported a strong relationship between oil prices and exchange rate volatility. Kunkler and MacDonald (2019) attempted to exclude the numéraire effect (see German et al. 1995 for the numéraire effect) in evaluating the co-movements between oil prices and G-10 countries' currencies. They examined the spillover and causal interference from the oil market to those currencies. Using intraday data, many recent studies (such as Andersen et al. 2007; Degiannakis 2008; Corsi et al. 2010; Bekaert and Hoerova 2014; Duong and Swanson 2015; Bollerslev et al. 2016; Wang et al. 2016a, b; Tian et al. 2017; Gong and Lin 2018a) have found there is a causal relationship between oil prices and currency markets. Research on the return and volatility spillovers among 18 cryptocurrencies indicated that Bitcoin is a key contributor to return-volatility spillover across all cryptocurrencies, which implies a high degree of interconnectedness and interdependence amongst cryptocurrencies (Koutmos 2018).

Another strand of literature investigates the relationship between oil prices and product prices. Serletis (1994) and Gjolberg and Johnsen (1999) reported the existence of a longrun equilibrium, while Adrangi et al. (2001) and Asche et al. (2003) emphasized the role of a unidirectional causal relationship. Generally, crude oil and product prices have strong dynamics. Product prices have played an important role in explaining short-run and longrun petroleum markets. This effect is stronger in the European market than in the US market (Lanza et al. 2005). Using intraday oil prices, previous studies (see in Sévi 2014; Haugom et al. 2014; Prokopczuk et al. 2016; Phan et al. 2016; Wen et al. 2016; Gong and Lin 2017; Degiannakis and Filis 2017; Liu et al. 2017; Ma et al. 2017; Gong and Lin 2018b; Ma et al. 2019) sought to model oil's stochastic dynamics (including price and volatility).

When it comes to the connections between the different oil and other markets, several papers have contributed to the literature. For example, Lin and Tamvakis (2001) indicated the connection between NYMEX and International Petroleum Exchange (IPE) crude oil. They emphasized the spillover effects particularly when two markets are trading at the same time. Sadorsky (2012) proved that the MGARCH model would better than the conventional GARCH to detect contagion volatility and asymmetric effects on international oil markets. Similarly, Liu and Tu (2012) suggest the diversification from defining the correlation $^{3}$ among five types of petroleum future contracts. This means that understanding the connection of these markets is important for the purpose of valuation of these assets. Moreover, Furió and Chuliá (2012) found dependency between Brent crude oil (known

\footnotetext{
3 The investors are advised to minimize the variance by adding the opposite direction of correlation indices.
} 
in Europe) and Zeebrugge natural gas forward prices and also reported a causal relationship in both markets. Furthermore, Jiao et al. (2007) and Chen et al. (2009) explored the economic transmission from the Chinese oil and international oil markets, which is considered to be of vital importance in understanding the interconnectedness of two different oil markets.

Indeed, there is a large amount of empirical evidence on the role of oil in economic activities. For example, Pindyck (2003), Brown and Yucel (2008), Zamani (2016), Jadidzadeh and Serletis (2017), Serletis and Rangel-Ruiz (2004), Bachmeier and Griffin (2006), Ramberg and Parsons (2010), Brigida (2014) and Atil et al. (2014) investigated the relationship between crude oil prices and natural gas prices. Although there are inconsistent results in terms of strong evidence or weak evidence, these studies suggest crude oil can be a market dominant for natural gas.

The relationship between crude oil and other commodities and currencies is well established in the energy literature. With the emergence of the new cryptocurrencies, a handful of studies have investigated the relationship between cryptocurrencies and oil prices. Van Wijk (2013) found that Bitcoin had a negative relationship to oil prices. Employing the Vector Error Correction Model, this author also examined the relationship of Bitcoin to other types of financial assets. However, these relationships were explored for only that particular cryptocurrency, ignoring other prominent cryptocurrencies. Most cryptocurrencies have been developed using the first version of Bitcoin or using a decentralized version (version 2.0) such as Ethereum (ETH) or Ripple (XRP) or Litecoin (LTC). Therefore, an examination of causal relationships is necessary to explain the spillover or contagion effects across these markets. Wang et al. (2016a) found that trading activities on oil markets influenced Bitcoin returns and volatilities. However, Wang et al. (2016b) focused on only one kind of cryptocurrency and their methodology was mainly based on linear assumptions. Guesmi et al. (2018) argue that Bitcoin can be used for hedging. If investors have the option to add assets to their portfolio of gold, oil and equities, Bitcoin will be an optimal option to minimize the overall risk of the portfolio. Using quantile-andquantile regression and CoVaR, Selmi et al. (2018) argued that, by using Bitcoin, investors may earn higher returns in the hedging process than they can with oil and gold. Recently, Gajardo et al. (2018) employed the Multifractal Asymmetric Detrended Cross-correlation analysis method to examine the relationship between Bitcoin and stock (through DJIA), gold and several major currencies. The results showed that Bitcoin has an asymmetric correlation with other financial assets; however, this phenomenon is evident only in the short run. Symitsi and Chalvatzis (2019) presented new insights relating to the economic value of Bitcoin. They found that an oil portfolio consisting of Bitcoin generates higher riskadjusted returns.

With the growing momentum of research on cryptocurrencies and energy products, we will briefly summarize here the current literature on the linkage between cryptocurrency and crude oil. First, Gronwald (2019) considered whether Bitcoin could be considered a commodity asset or not. If so, a co-movement with the commodity market would be expected. Using jump-GARCH and short-run supply-demand shocks, Gronwald drew the conclusion that Bitcoin has the characteristic of an exhaustible commodity resource, similar to crude oil. This could result in the co-movement of these two kinds of assets. Although Giudici and Abu-Hashish (2019) found that oil has no link to Bitcoin prices, several studies have reported a relationship between these two assets, for example Gajardo et al. (2018), using cross-correlation dependence. Similarly, Jin et al. (2019) concluded that Bitcoin prices are susceptible to price fluctuations from oil by using MF-DCCA and MV-GARCH. Therefore, we can conclude that the evidence on 
the relationship between Bitcoin and crude oil is inconclusive. In addition, this paper not only examines the directional impact of Bitcoin but also considers the other main cryptocurrencies.

In brief, a vast amount of empirical work has examined the relationship between oil prices and other kinds of financial/non-financial assets. Nevertheless, the relationship between cryptocurrencies (as monetary currencies) and crude oil has received limited academic attention. Using a more sophisticated estimation ('Entropy Transfer'), this paper contributes to the embryonic literature on the transmission channel from oil shocks to the cryptocurrency market.

\section{Empirical methodology and data}

In this section we present our main estimation approach. Because of the complexity of data or stochastic processes, methods previously used to calculate information transfer have been mainly derived from assumptions of specific subjects (or sometimes the process-built restrictions). An important challenge faced by energy researchers is to quantify the informational flow, as the Vector Auto Regression (VAR) approach cannot estimate this relationship. Therefore, we employ 'Entropy Transfer', which is considered a more robust method (Schreiber 2000) to overcome the methodological concerns raised over previous approaches. In addition, Granger (1988) causality underperform for structural models. Thus, Transfer Entropy is used here to measure the large amount of asymmetric information and large networks in non-parametrically directed processes.

For example, if we consider two processes, I and J, the Transfer Entropy is defined as:

Transfer entropy from $\mathrm{J}$ to $\mathrm{I}=\left(\right.$ Information for future observation $\mathrm{I}_{(\mathrm{t}+1)}$ absorbed from historical values of $\mathrm{I}$ and $\mathrm{J}$ )

$$
\text { - (Information for future observation } \mathrm{I}_{(\mathrm{t}+1)} \text { absorbed from the historical value of only } \mathrm{I} \text { ) }
$$

Then, Shannon (1948) entropy was defined as the independently encoded drawing:

$$
\mathrm{H}_{\mathrm{J}}=-\sum_{\mathrm{j}} \mathrm{p}(\mathrm{j}) \cdot \log (\mathrm{p}(\mathrm{j}))
$$

in which, $\mathrm{J}$ is a discrete random variable with probability distribution $\mathrm{p}(\mathrm{j})$ and $\mathrm{j}$ stands for the different outcomes that this variable can take. Therefore, $\mathrm{H}$ is considered the optimal value. However, Shannon's formula works well under uncertainty. Combined with the theoretical framework of Kullback and Leibler (1951), the Shannon process was further expanded into two processes, I and J, with the strict assumption that the time series should be stationary, for marginal probability distribution $p(i), p(j)$ and joint distribution $p(i, j)$. Following this, the average number of encoded observations for $(t+1)$ and value $(k)$ :

$$
h_{I}(k)=-\sum_{i} p\left(i_{t+1}, i_{t}^{(k)}\right) \cdot \log \left(p\left(i_{t+1} \mid i_{t}^{(k)}\right)\right)
$$

where $i_{t}^{(k)}=\left(i_{t}, \ldots, i_{t-k+1}\right) \cdot h_{J}(l)$ is considered analogously for process $\mathrm{J}$. Then, with the generalized Markov process $p\left(i_{t+1} \mid i_{t}^{(k)}\right)=p\left(i_{t+1} \mid i_{t}^{(k)}, j_{t}^{(k)}\right)$ from Kullback and Leibler (1951). We then have the Shannon (1948) transfer entropy given as: 


$$
T_{J \rightarrow I}(k, l)=\sum_{i, j} p\left(i_{t+1}, i_{t}^{(k)} j_{t}^{(l)}\right) \cdot \log \left(\frac{\left(i_{t+1} \mid i_{t}^{(k)}, j_{t}^{(k)}\right)}{\left(i_{t+1} \mid i_{t}^{(k)}\right)}\right)
$$

where $T_{J \rightarrow I}$ evaluates the information flow from $\mathrm{J}$ to $\mathrm{I}$.

Applying the 'Transfer Entropy' process, we generalize information flows from variable Y to variable $\mathrm{X}$ in the following formula:

$$
\begin{aligned}
T E_{Y \rightarrow X}(k, l)= & \sum_{i_{n+1}, i_{n}^{k} j_{n}^{l}} p\left(i_{n+1} i_{n}^{k}, j_{n}^{l}\right) \log _{2} p\left(i_{n+1} \mid i_{n}^{k}, j_{n}^{l}\right) \\
& -\sum_{i_{n+1}, i_{n}^{k}, j_{n}^{l}} p\left(i_{n+1} i_{n}^{k}, j_{n}^{l}\right) \log _{2} p\left(i_{n+1} \mid i_{n}^{k}\right) \\
= & \sum_{i_{n+1}, i_{n}^{k} j_{n}^{l}} p\left(i_{n+1} i_{n}^{k}, j_{n}^{l}\right) \log _{2} \frac{p\left(i_{n+1} \mid i_{n}^{k}, j_{n}^{l}\right)}{p\left(i_{n+1} \mid i_{n}^{k}\right)}
\end{aligned}
$$

in which $i_{n}$ is the nth component of the time series of variable $X$ and $j_{n}$ is component $n$ of the time series of variable $\mathrm{Y}$.

The joint probability of $\mathrm{X}$ and $\mathrm{Y}$ is defined as:

$$
p\left(i_{n+1}, i_{n}^{(k)}, j_{n}^{(l)}\right)=p\left(i_{n+1}, i_{n}, \ldots, i_{n-k+1}, j_{n}, \ldots, j_{n-l-1}\right)
$$

Then, Erdös and Rényi (1970) introduced a new approach based on this with weighting parameter $\mathrm{q}>0$ for individual probabilities $\mathrm{p}(\mathrm{j})$.

$$
H_{J}^{q}=\frac{1}{1-q} \log \left(\sum_{j} p^{q}(j)\right)
$$

As $q \rightarrow 1$, Rényi entropy will converge to Shannon entropy while $0<q<1$ means low probability with more weight. Otherwise, $q>1$ means a higher initial probability for preference of outcome j. Endowing the escort distribution, Beck and Schlögl (1993) indicated the parameter $\phi_{q}(j)=\frac{\mathrm{p}^{q}(\mathrm{j})}{\sum_{\mathrm{j}} \mathrm{p}^{q}(\mathrm{j})}$, with $\mathrm{q}>0$ in order to normalize the weighted distribution. Jizba et al. (2012) developed the Rényi entropy, which we employed as follows:

$$
R T_{J \rightarrow I}(k, l)=\frac{1}{1-q} \log \left(\frac{\sum_{i} \phi_{q}\left(i_{t}^{(k)}\right) p^{q}\left(i_{t+1} \mid i_{t}^{(k)}\right)}{\sum_{i, j} \phi_{q}\left(i_{t}^{(k)}, j_{t}^{(k)}\right) p^{q}\left(i_{t+1} \mid i_{t}^{(k)}, j_{t}^{(k)}\right)}\right)
$$

The process of Shannon and Rényi Transfer Entropy is based on discrete random data. Then, the process is based on the Markov block bootstrap (Dimpfl and Peter 2013) and repeated by bootstrap. Finally, the null hypothesis for transferring entropy states that no information is transferred. We also generalize the Rényi Transfer Entropy:

$$
R_{Y \rightarrow X}(k, l)=\frac{1}{1-q} \log _{2} \frac{\sum_{i_{n+1}, i_{n}^{k}} \varphi_{q}\left(i_{n}^{k}\right) p^{q}\left(i_{n+1} \mid i_{n}^{k}\right)}{\sum_{i_{n+1}, i_{n}^{k}} \varphi_{q}\left(i_{n}^{k}, j_{n}^{l}\right) p^{q}\left(i_{n+1} \mid i_{n}^{k}, j_{n}^{l}\right)}
$$


where $\varphi_{q}$ is the escort distribution given by:

$$
\varphi_{q}(i)=\frac{p^{q}(i)}{\sum_{i} p_{i}^{q}}
$$

The methodology of 'Transferring Entropy' is not only used by computer science researchers (e.g. Lizier et al. 2008; Lizier and Mahoney 2013), but has also been applied in many other interdisciplinary fields, for example in: neurosciences to detect neural cortex (Sumioka et al. 2007; Faes et al. 2013), social network and behaviors (Ver Steeg and Galstyan 2012); mathematical statistics (Barnett and Bossomaier 2012; Liu et al. 2014); and, especially, in thermodynamics (Prokopenko et al. 2013).

The applications of 'Transferring Entropy' in economics and finance is an emerging methodological development. Next, we briefly evaluate the application of this method in economics and finance. Marschinski and Kantz (2002) introduced this method to evaluate the information flow from the S\&P500 Index (USA)DAX (Germany). They found it provided more efficient and consistent estimations compared with other approaches as it subtracts the effects of noise as well as high volatility in the time series. Baek et al. (2005) employed this method to investigate the impact of energy industry returns on the overall health of an economy. Their sample covered 135 firms listed on the New York Stock Exchange over the period 1983 to 2003, and they found that energy companies significantly influence the national economy. Interestingly, these results are in line with the paper by Kwon and Yang (2008) which reported on information flows from the US and European markets to the Asia Pacific region. Furthermore, Jizba et al. (2012) reexamined the work of Marschinski and Kantz (2002) with the integration of two methodological approaches (Shannon's entropy and Rényi's entropy). They also investigated the non-parametric distribution in terms of information transfer. Similarly, Dimpfl and Peter (2013) and Peter et al. (2011) investigated the information flow from the CDS (Credit Default Swap) market to the corporate bond market by applying the 'Transfer Entropy' approach. The results reveal a dynamic relationship of market risk (measured by CBOE Volatility Index-VIX) among different financial assets. Kim et al. (2013) analysed a set of variables including the equity index, consumer price index, real exchange rate, trade balance and industrial production index, representing macroeconomic determinants, from 18 economies over the period 1990-2000. They studied the interconnectedness among their samples and showed the US market was a net sender of information flows, whereas Europe appeared to be a passive recipient. Li et al. (2013) adapted this new perspective of 'Transferring Entropy' to investigate the contagion risks among Chinese banks by simulating the spillover risks of networks, and concluded that Chinese banks are likely to be stable under market risks.

In brief, several previous studies have applied Transfer Entropy to investigate causal relationships in different institutional and market settings. However, we are not aware of any study that has applied Transfer Entropy to investigate connections between the crude oil markets and the cryptocurrency markets. Therefore, our paper extends the application of this quantitative technique to investigate the causal relationship between the US and European crude oil returns and 14 different cryptocurrencies.

Our daily returns data are sorted into two main groups: First, oil returns data for the US index (DCOILWTICO) and European index (DCOILBRENTEU) are collected from Federal Reserve Economic Data (https://fred.stlouisfed.org/). Noticeably, we focus on the developed regions only, specifically, the US and EU crude oil markets due to the large proportion of these developed economies in global crude oil market (Chuliá et al. 2019). Furthermore, Jin et al. (2012) also indicated that Dubai crude oil has similar properties to 
Table 1 Summary statistics

\begin{tabular}{llllllrr}
\hline Variable & Obs. & Mean & SD & Min & Max & Skewness & Kurtosis \\
\hline DCOILWTICO & 1168 & 0.0005 & 0.0221 & -0.0905 & 0.1128 & 0.2535 & 5.8424 \\
DCOILBRENTEU & 1168 & 0.00004 & 0.0200 & -0.0690 & 0.0989 & 0.4333 & 5.7238 \\
BTC & 2169 & 0.0016 & 0.0433 & -0.2674 & 0.3614 & -0.1108 & 11.0616 \\
LTC & 2169 & 0.0013 & 0.0668 & -0.5192 & 0.8245 & 1.7000 & 27.7714 \\
ETH & 1338 & 0.0030 & 0.0763 & -1.3739 & 0.4034 & -4.0516 & 83.2739 \\
XEM & 1466 & 0.0035 & 0.0876 & -0.5025 & 1.0684 & 1.9692 & 23.8385 \\
DASH & 1877 & 0.0034 & 0.0777 & -0.4204 & 1.0668 & 2.5294 & 31.6831 \\
DOGE & 1938 & 0.0009 & 0.0808 & -0.6257 & 1.0625 & 1.5506 & 29.0534 \\
XMR & 1781 & 0.0018 & 0.0740 & -0.4404 & 0.5676 & 0.5846 & 9.01816 \\
VTC & 1902 & 0.0010 & 0.1118 & -0.6141 & 1.0923 & 2.2348 & 19.9729 \\
XVG & 1624 & 0.0044 & 0.1722 & -0.9162 & 1.9169 & 1.1696 & 16.0909 \\
DBG & 1885 & 0.0012 & 0.1024 & -0.6035 & 1.1522 & 1.8588 & 20.8781 \\
XLM & 1705 & 0.0021 & 0.0793 & -0.3334 & 0.7040 & 1.9281 & 17.8684 \\
USDT & 1501 & -0.0001 & 0.0120 & -0.1822 & 0.1511 & -2.3979 & 110.783 \\
MAID & 1804 & 0.0012 & 0.0694 & -0.4020 & 0.4643 & 0.17116 & 7.03972 \\
XRP & 2071 & 0.0019 & 0.0758 & -0.6011 & 1.0109 & 2.0258 & 30.2785 \\
\hline
\end{tabular}

Transfer Entropy allows us to estimate the causal relationship based on the unbalanced data. Our sample covers the period from 29th April 2013 to 06th April 2019 with different observations for our variables

Brent. Most importantly, WTI crude oil which has been traded in the New York Mercantile Exchange (NYME), the biggest commodity futures. This is the most crucial pricing benchmarks in the global crude oil which could be considered as an important criterion for investors. In a recent study, Liu and Gong (2020) confirmed that WTI plays a prominent role in the international crude oil markets. Concomitantly, examining the relationship between the two largest crude oil markets and an inclusive sample of cryptocurrency coins by employing new econometrics models would provide us with deeper insights into the spill-over effects.

Second, data on 14 cryptocurrencies are collected from coinmarketcap.com. These currencies are: BTC (Bitcoin), LTC (Litecoin), ETH (Ethereum), XEM (Nem), DASH (Dash), DOGE (Dogecoin), XMR (Monero), VTC (Vertcoin), XVG (Verge), DGB (Digibyte), XLM (Stellar), USDT (Tether), MAID (MaidSafeCoin), XRP (Ripple). Our sample period covers data from 29th April 2013 to 06th April 2019, though not all cryptocurrencies were in existence over the whole period. We chose a long horizon to cover as much information as possible. In addition, one of Transfer Entropy's advantages is that is allows unbalanced datasets to be used to estimate causal relationships. From the available pool of all cryptocurrencies, we selected those that met three main criteria: (i) continuous trading; (ii) having an equal number of or more observations than DCOILWTICO and DCOILBRENTEU; and (iii) accounted for at least $80 \%$ market capitalization of the cryptocurrency market. Further information regarding market capitalization, circulating supply and date of issue are provided in "Appendix" (ii). In Table 1, we report the descriptive statistics for our sample. 


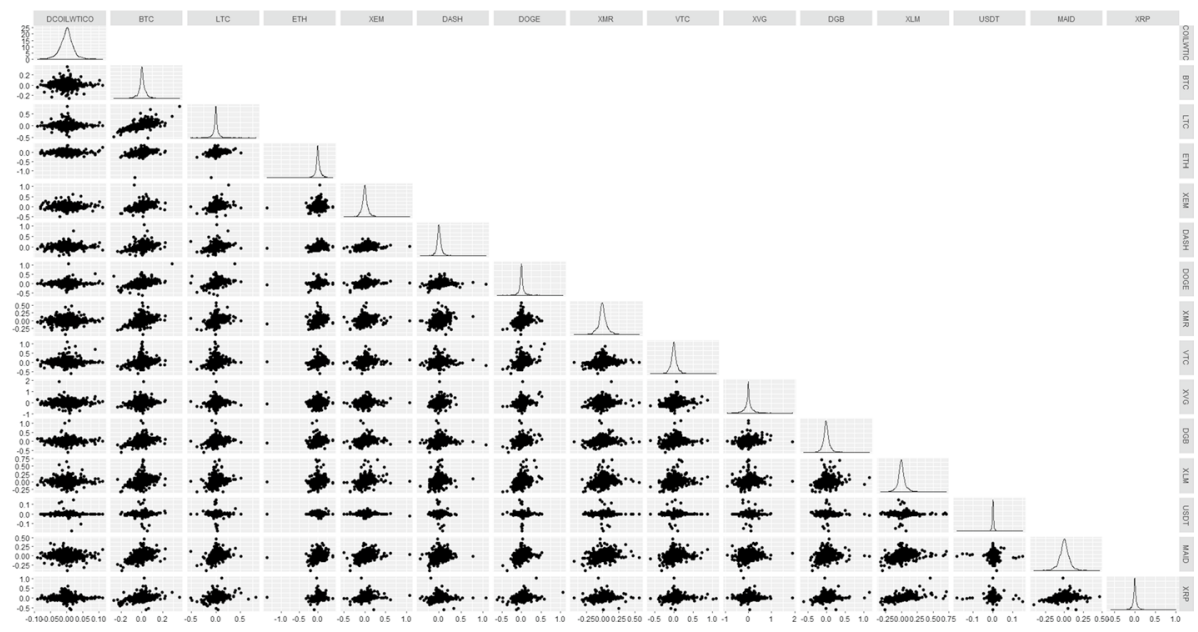

Fig. 1 Data Distribution and Correlation between the US Crude Oil Index and each Cryptocurrency. Note The correlation data have non-normal distribution (not linear). Furthermore, some dataset structures are skewed and heavy-tailed. Interestingly, there are some outliers correlated with the US crude oil index, which means that the dots are at a distance from the sample plot

Following Miller and Scholes (1972), ${ }^{4}$ we continued data processing to calculate the index return by logarithm return. ${ }^{5}$ Table 1 presents the characteristics of WTI and BRENT EU indices returns as well as 14 cryptocurrencies in terms of daily trading activities. Overall, the mean daily return is approximately zero. Except for Bitcoin, Ethereum and USDT, the other variables show positive skewness, which indicates that these coins have positive extreme values in the datasets. Bitcoin, Ethereum and USDT are likely to have negative extreme values. With regard to kurtosis analysis, all variables have a heavy tail distribution, with the probability of extreme values in both tails. Surprisingly, Ethereum has the highest kurtosis value (83.27397) whereas the oil prices (in the US and Europe) have the lowest values (5.842435 and 5.723816, respectively). We therefore reject all the assumptions relating to normal distribution, implying there is an interconnectedness in the abnormal distribution of variables. Therefore, we employ the entropy approach to investigate the causal relationship between crude oil markets and cryptocurrencies.

To define the data structures as well as their characteristics, plots are combined into a plot matrix. We then need to employ Transfer Entropy for further quantitative testing. Hence, Transfer Entropy is employed to capture the informational flows among these markets, assuming that the vast majority of information will have interacted. These results are likely to be robust, owing to the correction of selecting information by crude oil markets to cryptocurrencies through tensor of blockchains of these cryptocurrencies. Clearly, the anomalous distributions among our variables raises concerns that we need to employ the econphysics technique to estimate the informational flows to eliminate the outliers, and that we need to employ data transformation in order for our results to be robust (Figs. 1 and 2).

\footnotetext{
$4 r_{\mathrm{t}}=\ln \left(\frac{P_{\mathrm{t}}}{P_{\mathrm{t}-1}}\right)$ in which $\mathrm{P}_{\mathrm{t}}$ is the index at time $t$.

5 Many recent papers have applied this methodology for Bitcoin returns, but see in particular Jiang et al. (2018) and Sensoy (2019).
} 


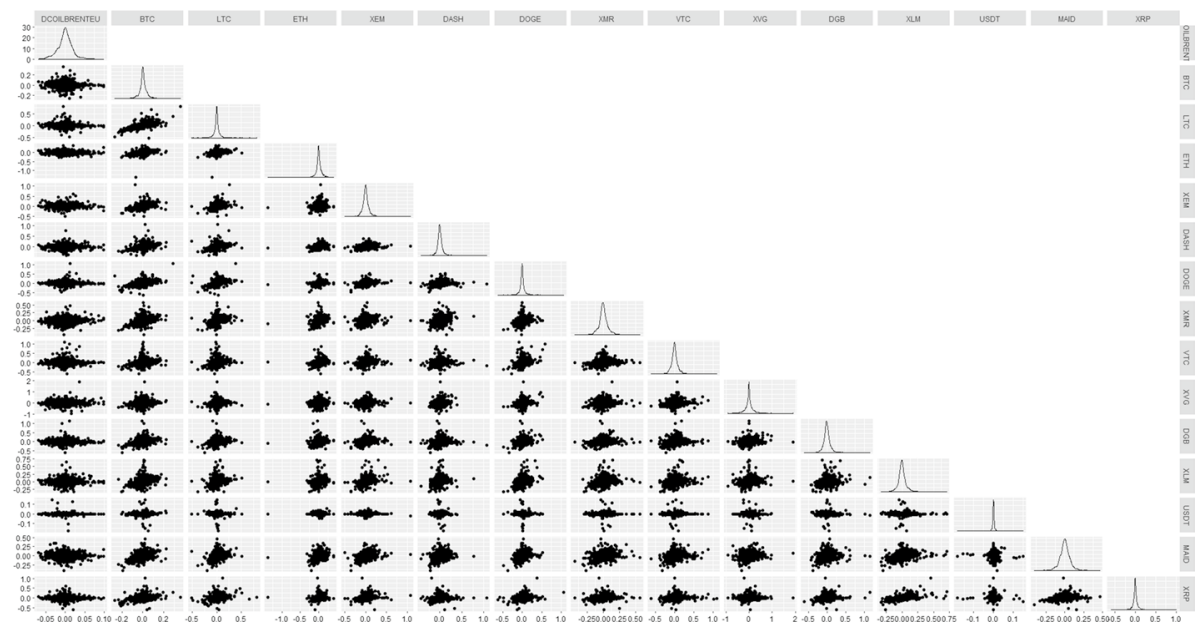

Fig. 2 Data Distribution and Correlation between the European Crude Oil Index and each Cryptocurrency. Note The correlation data have a non-normal distribution (not linear). Furthermore, some dataset structures are skewed and heavy-tailed. Interestingly, there are some outliers correlated with the European crude oil index, which means that the dots are at a distance from the sample plot

Table 2 Linear correlation analysis

\begin{tabular}{lrr}
\hline Cryptocurrencies & DCOILWTICO & DCOILBRENTEU \\
\hline BTC & 0.0041 & -0.0262 \\
LTC & -0.0012 & -0.0333 \\
ETH & -0.0019 & -0.0258 \\
XEM & -0.0032 & -0.0084 \\
DASH & 0.0516 & 0.0252 \\
DOGE & 0.0446 & 0.0411 \\
XMR & 0.0120 & 0.0494 \\
VTC & 0.0319 & 0.0183 \\
XVG & -0.0158 & 0.0323 \\
DBG & 0.0202 & 0.0073 \\
XLM & -0.0020 & 0.0331 \\
USDT & -0.0283 & -0.0179 \\
MAID & -0.0312 & -0.0281 \\
XRP & -0.0193 & -0.0221 \\
\hline
\end{tabular}

None of the correlations is statistically significant even at the $10 \%$ level

\section{Empirical findings and discussion}

\subsection{Linear correlation analysis}

First, we employed the linear correlation using a Bonferroni-adjusted significance level and the empirical results are reported in Table 2. Table 2 shows the empirical linear correlations between DCOILWTICO, DCOILBRENTEU and the 14 cryptocurrencies. 
Table 3 Unit root analysis

\begin{tabular}{|c|c|c|}
\hline Variables & $\begin{array}{l}\text { Augmented Dickey- } \\
\text { Fuller }\end{array}$ & Phillips-Perron \\
\hline DCOILWTICO & $-32.920 * * *$ & $-32.796 * * *$ \\
\hline DCOILBRENTEU & $-28.557 * * *$ & $-28.580 * * *$ \\
\hline BTC & $-46.438 * * *$ & $-46.466 * * *$ \\
\hline LTC & $-45.736 * * *$ & $-45.798 * * *$ \\
\hline ETH & $-34.781 * * *$ & $-34.743 * * *$ \\
\hline XEM & $-42.069 * * *$ & $-41.977 * * *$ \\
\hline DASH & $-43.387 * * *$ & $-43.393 * * *$ \\
\hline DOGE & $-40.463 * * *$ & $-40.378 * * *$ \\
\hline XMR & $-42.506 * * *$ & $-42.511 * * *$ \\
\hline VTC & $-41.902 * * *$ & $-41.898 * * *$ \\
\hline XVG & $-53.220 * * *$ & $-52.886^{* * * *}$ \\
\hline DBG & $-43.755^{* * *}$ & $-43.780 * * *$ \\
\hline XLM & $-38.836 * * *$ & $-38.884 * * *$ \\
\hline USDT & $-26.252 * * *$ & $-24.939 * * *$ \\
\hline MAID & $-47.360 * * *$ & $-47.374 * * *$ \\
\hline XRP & $-42.666^{* * * *}$ & $-42.933 * * *$ \\
\hline
\end{tabular}

The symbols $*, * *$, and $* * *$ denote the level of significance at the $10 \%, 5 \%$, and $1 \%$ levels, respectively

There is no correlation between crude oil returns and cryptocurrency values. The correlation values are around zero and statistically insignificant. The results from linear correlation therefore suggest there is no connection between crude oil and cryptocurrencies. However, in fact, the transmission of information still happens. Therefore, we need to further investigate the connections among these relationships (including itself and between oil(s) and cryptocurrencies).

\subsection{Unit root analysis}

Before employing further estimation techniques, we need to test the stationary of all the variables. Table 3 gives a summary of stationarity tests such as Augmented Dickey-Fuller and Phillips-Perron. The purpose of having the stationary time series datasets is to ensure the results are unbiased and not spurious.

All variables are stationary at the $1 \%$ significance level from the original series. This shows that crude oil and cryptocurrency returns are integrated at $\mathrm{I}(0)$.

\subsection{Transfer entropy analysis}

In Table 4, we present the results of Renyi and Shannon (threshold) Transfer Entropy between the US crude oil index (DCOILWTICO) index returns and the 14 cryptocurrencies.

Interestingly, only six cryptocurrencies have a causal relationship with DCOILWTICO. Only two cryptocurrencies have a bilateral relationship, with shocks from US crude oil to DASH and XVG, and vice versa. DASH is a bitcoin-based currency featuring instant transactions, decentralized governance and budgeting, and private transactions. Consequently, DASH has similar characteristics as Bitcoin but comes with more advanced features such as 
Table 4 Renyi and Shannon transfer entropy results from DCOILWTICO to Cryptocurrency Markets

\begin{tabular}{|c|c|c|}
\hline Causality & Renyi transfer entropy & $\begin{array}{l}\text { Shannon } \\
\text { transfer } \\
\text { entropy }\end{array}$ \\
\hline DCOILWTICO $\rightarrow$ BTC & $\begin{array}{l}0.0083 \\
{[0.0027]}\end{array}$ & 0.0080 \\
\hline $\mathrm{BTC} \rightarrow \mathrm{DCOILWTICO}$ & $\begin{array}{l}0.0081 \\
{[0.0025]}\end{array}$ & \\
\hline DCOILWTICO $\rightarrow$ LTC & $\begin{array}{l}0.0117^{*} \\
{[0.0028]}\end{array}$ & 0.0116 \\
\hline LTC $\rightarrow$ DCOILWTICO & $\begin{array}{l}0.0042 \\
{[0.0024]}\end{array}$ & \\
\hline DCOILWTICO $\rightarrow$ ETH & $\begin{array}{l}0.0268 * * * \\
{[0.0043]}\end{array}$ & 0.0267 \\
\hline ETH $\rightarrow$ DCOILWTICO & $\begin{array}{l}0.0055 \\
{[0.0042]}\end{array}$ & \\
\hline DCOILWTICO $\rightarrow$ XEM & $\begin{array}{l}0.0145 \\
{[0.0040]}\end{array}$ & 0.0144 \\
\hline $\mathrm{XEM} \rightarrow$ DCOILWTICO & $\begin{array}{l}0.0089 \\
{[0.0037]}\end{array}$ & \\
\hline DCOILWTICO $\rightarrow$ DASH & $\begin{array}{l}0.0171 * * \\
{[0.0032]}\end{array}$ & 0.0170 \\
\hline DASH $\rightarrow$ DCOILWTICO & $\begin{array}{l}0.0140 * \\
{[0.0033]}\end{array}$ & \\
\hline DCOILWTICO $\rightarrow$ DOGE & $\begin{array}{l}0.0109 \\
{[0.0028]}\end{array}$ & 0.0108 \\
\hline DOGE $\rightarrow$ DCOILWTICO & $\begin{array}{l}0.0102 \\
{[0.0030]}\end{array}$ & \\
\hline DCOILWTICO $\rightarrow$ XMR & $\begin{array}{l}0.0136^{*} \\
{[0.0032]}\end{array}$ & 0.0136 \\
\hline $\mathrm{XMR} \rightarrow$ DCOILWTICO & $\begin{array}{l}0.0052 \\
{[0.0036]}\end{array}$ & \\
\hline DCOILWTICO $\rightarrow$ VTC & $\begin{array}{l}0.0076 \\
{[0.0031]}\end{array}$ & 0.0076 \\
\hline VTC $\rightarrow$ DCOILWTICO & $\begin{array}{l}0.0045 \\
{[0.0031]}\end{array}$ & \\
\hline DCOILWTICO $\rightarrow$ XVG & $\begin{array}{l}0.0132^{*} \\
{[0.0033]}\end{array}$ & 0.0131 \\
\hline XVG $\rightarrow$ DCOILWTICO & $\begin{array}{l}0.0184 * * \\
{[0.0035]}\end{array}$ & \\
\hline DCOILWTICO $\rightarrow$ DGB & $\begin{array}{l}0.0104 \\
{[0.0032]}\end{array}$ & 0.0103 \\
\hline DGB $\rightarrow$ DCOILWTICO & $\begin{array}{l}0.0065 \\
{[0.0031]}\end{array}$ & \\
\hline $\mathrm{XLM} \rightarrow$ DCOILWTICO & $\begin{array}{l}0.0070 \\
{[0.0036]}\end{array}$ & 0.0069 \\
\hline DCOILWTICO $\rightarrow$ XLM & $\begin{array}{l}0.0103 \\
{[0.0032]}\end{array}$ & \\
\hline DCOILWTICO $\rightarrow$ USDT & $\begin{array}{l}0.0122 \\
{[0.0036]}\end{array}$ & 0.0122 \\
\hline USDT $\rightarrow$ DCOILWTICO & $\begin{array}{l}0.0075 \\
{[0.0038]}\end{array}$ & \\
\hline
\end{tabular}


Table 4 (continued)

\begin{tabular}{lll}
\hline Causality & Renyi transfer entropy & $\begin{array}{l}\text { Shannon } \\
\text { transfer } \\
\text { entropy }\end{array}$ \\
\hline DCOILWTICO $\rightarrow$ MAID & $0.0107^{*}$ & 0.0106 \\
& {$[0.0031]$} & \\
MAID $\rightarrow$ DCOILWTICO & 0.0056 & \\
& {$[0.0035]$} & 0.0093 \\
DCOILWTICO $\rightarrow$ XRP & 0.0094 & \\
& {$[0.0027]$} \\
$\mathrm{XRP} \rightarrow$ DCOILWTICO & 0.0103 & \\
& {$[0.0027]$} & \\
\hline
\end{tabular}

The symbols $*, * *$, and $* * *$ denote significance at the $10 \%, 5 \%$, and $1 \%$ levels, respectively
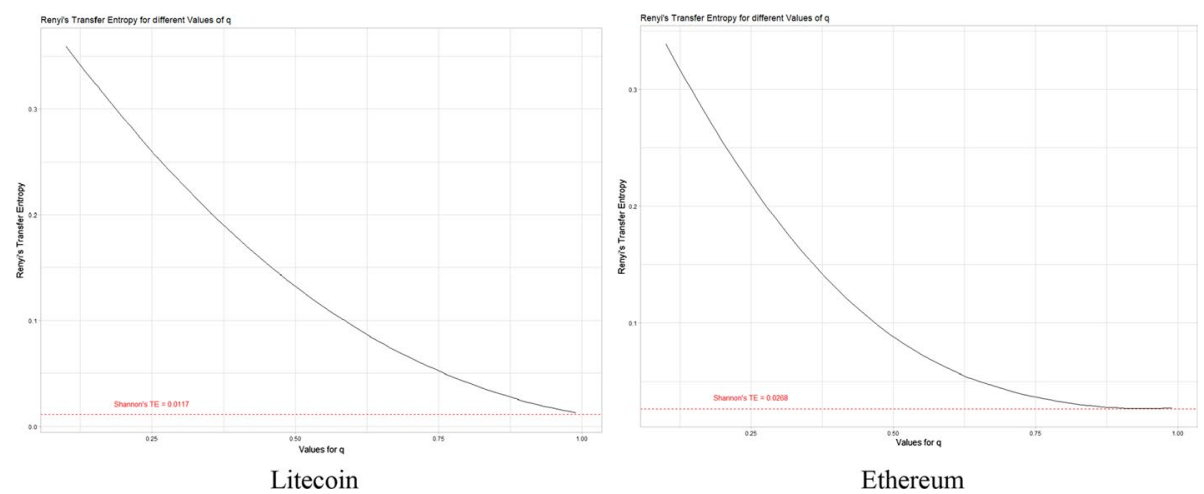

Fig. 3 Rényi transfer entropy with different values of q from the US Crude Oil Market

private information and transactions. Therefore, it is cogent to use it as a payment method. Furthermore, the XVG is a technological platform based on the Tor Project. ${ }^{6}$ Interestingly, the Tor project was received a lot of offers from the United States National Agencies for developing their platforms; for example, The National Security Agency (NSA) (Guardian 2013). Therefore, the effects of XVG on the US crude oil could be explained by the broad interest of technological and advanced platform which is designed.

In terms of transmission from the US crude oil market returns on cryptocurrency returns, the findings of Shannon transfer entropy estimation indicate a significant information flow from the US crude oil to six of the cryptocurrencies (LTC, ETH, DASH, XMR, XVG and MAID). This is evidence of information flows from the US crude oil market returns to cryptocurrency markets. It supports the proposition that the macroscopic economic value of the US crude oil has an effect on the cryptocurrency markets.

The process of transferring entropy from the US crude oil market to the cryptocurrency market lies in the range 1.1\% (weakest at Litecoin) to 2.6\% (strongest at Ethereum). Taking the Rényi's transfer entropy through these graphs (in Fig. 3), we can further investigate this

$\overline{6}$ Please see more at https://www.torproject.org/. 
Table 5 Renyi and Shannon transfer entropy results from DCOILBRENTEU to Cryptocurrency Market

\begin{tabular}{|c|c|c|}
\hline Causality & Renyi transfer entropy & $\begin{array}{l}\text { Shannon } \\
\text { transfer } \\
\text { entropy }\end{array}$ \\
\hline DCOILBRENTEU $\rightarrow$ BTC & $\begin{array}{l}0.0113^{*} \\
{[0.0025]}\end{array}$ & 0.0112 \\
\hline $\mathrm{BTC} \rightarrow$ DCOILBRENTEU & $\begin{array}{l}0.0106^{*} \\
{[0.0026]}\end{array}$ & \\
\hline DCOILBRENTEU $\rightarrow$ LTC & $\begin{array}{l}0.0116^{*} \\
{[0.0028]}\end{array}$ & 0.0115 \\
\hline LTC $\rightarrow$ DCOILBRENTEU & $\begin{array}{l}0.0075 \\
{[0.0027]}\end{array}$ & \\
\hline DCOILBRENTEU $\rightarrow$ ETH & $\begin{array}{l}0.0177 * * \\
{[0.0041]}\end{array}$ & 0.0177 \\
\hline ETH $\rightarrow$ DCOILBRENTEU & $\begin{array}{l}0.0138 \\
{[0.0041]}\end{array}$ & \\
\hline DCOILBRENTEU $\rightarrow$ XEM & $\begin{array}{l}0.0088 \\
{[0.0038]}\end{array}$ & 0.0087 \\
\hline $\mathrm{XEM} \rightarrow \mathrm{DCOILBRENTEU}$ & $\begin{array}{l}0.0080 \\
{[0.0038]}\end{array}$ & \\
\hline DCOILBRENTEU $\rightarrow$ DASH & $\begin{array}{l}0.0118 \\
{[0.0028]}\end{array}$ & 0.0117 \\
\hline DASH $\rightarrow$ DCOILBRENTEU & $\begin{array}{l}0.0108 \\
{[0.0029]}\end{array}$ & \\
\hline DCOILBRENTEU $\rightarrow$ DOGE & $\begin{array}{l}0.0089 \\
{[0.0031]}\end{array}$ & 0.0089 \\
\hline DOGE $\rightarrow$ DCOILBRENTEU & $\begin{array}{l}0.0058 \\
{[0.0031]}\end{array}$ & \\
\hline DCOILBRENTEU $\rightarrow$ XMR & $\begin{array}{l}0.0128^{*} \\
{[0.0032]}\end{array}$ & 0.0127 \\
\hline $\mathrm{XMR} \rightarrow$ DCOILBRENTEU & $\begin{array}{l}0.0042 \\
{[0.0035]}\end{array}$ & \\
\hline DCOILBRENTEU $\rightarrow$ VTC & $\begin{array}{l}0.0112 \\
{[0.0031]}\end{array}$ & 0.0111 \\
\hline $\mathrm{VTC} \rightarrow$ DCOILBRENTEU & $\begin{array}{l}0.0052 \\
{[0.0029]}\end{array}$ & \\
\hline DCOILBRENTEU $\rightarrow$ XVG & $\begin{array}{l}0.0093 \\
{[0.0034]}\end{array}$ & 0.0093 \\
\hline $\mathrm{XVG} \rightarrow$ DCOILBRENTEU & $\begin{array}{l}0.0056 \\
{[0.0034]}\end{array}$ & \\
\hline DCOILBRENTEU $\rightarrow$ DGB & $\begin{array}{l}0.0076 \\
{[0.0031]}\end{array}$ & 0.0076 \\
\hline DGB $\rightarrow$ DCOILBRENTEU & $\begin{array}{l}0.0152 * * \\
{[0.0031]}\end{array}$ & \\
\hline $\mathrm{XLM} \rightarrow$ DCOILBRENTEU & $\begin{array}{l}0.0063 \\
{[0.0033]}\end{array}$ & 0.0062 \\
\hline DCOILBRENTEU $\rightarrow$ XLM & $\begin{array}{l}0.0063 \\
{[0.0036]}\end{array}$ & \\
\hline DCOILBRENTEU $\rightarrow$ USDT & $\begin{array}{l}0.0137 \\
{[0.0037]}\end{array}$ & 0.0137 \\
\hline USDT $\rightarrow$ DCOILBRENTEU & $\begin{array}{l}0.0077 \\
{[0.0037]}\end{array}$ & \\
\hline
\end{tabular}


Table 5 (continued)

\begin{tabular}{lll}
\hline Causality & Renyi transfer entropy & $\begin{array}{l}\text { Shannon } \\
\text { transfer } \\
\text { entropy }\end{array}$ \\
\hline DCOILBRENTEU $\rightarrow$ MAID & $0.0120^{*}$ & 0.0120 \\
& {$[0.0032]$} & \\
MAID $\rightarrow$ DCOILBRENTEU & 0.0065 & \\
& {$[0.0033]$} & 0.0061 \\
DCOILBRENTEU $\rightarrow$ XRP & 0.0061 & \\
& {$[0.0028]$} & \\
$\mathrm{XRP} \rightarrow$ DCOILBRENTEU & 0.0081 & {$[0.0030]$} \\
&
\end{tabular}

The symbols $* * *$, and $* * *$ denote the significance at the $10 \%, 5 \%$, and $1 \%$ levels, respectively

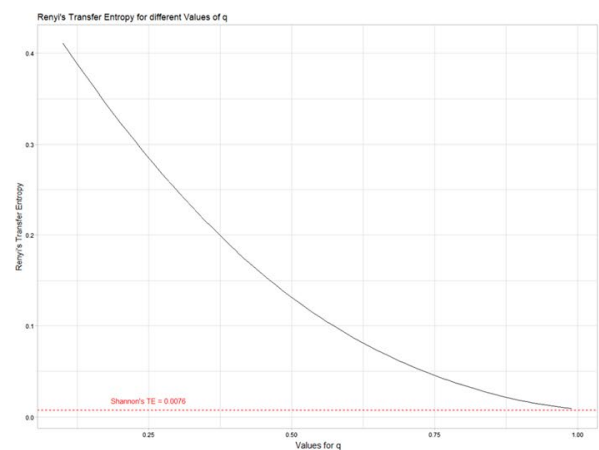

DGB

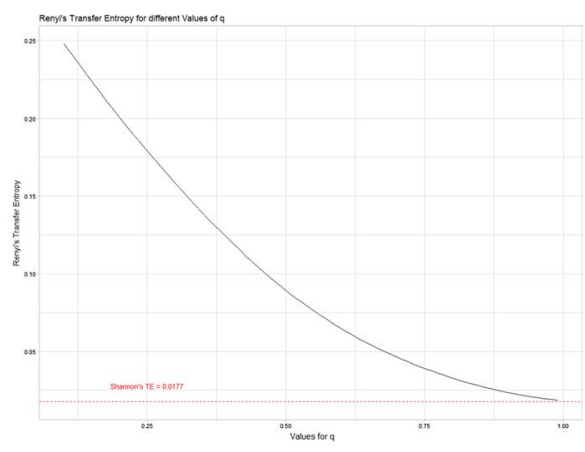

Ethereum

Fig. 4 Rényi transfer entropy with different values of q from the European Crude Oil Market

relationship. From the results presented in Fig. 3, there is a possibility to reweight the probabilities under Erdös and Rényi's (1970) methodology (mentioned in the previous section). The value of $q$ will converge to $1(\mathrm{q} \rightarrow 1)$. As can be seen, the value of transfer entropy of Litecoin and Ethereum is highest at the smallest value of (q) and decreases as q increases. Finally, it will converge in Shannon's TE.

Table 5 demonstrates the results of Renyi and Shannon (threshold) Transfer Entropy between DCOILBRENTEU index returns and the 14 cryptocurrencies.

Among the 14 cryptocurrencies, six have interconnectedness with DCOILBRENTEU. They are BTC, LTC, ETH, XMR, DGB, and MAID. Among them, only Bitcoin has a bilateral causal relationship with the European crude oil market, which means that there is a strong connection from Bitcoin to DCOILBRENTEU, and vice versa.

Generally, all the shocks from the European crude oil market lead to shocks on the cryptocurrency market, as evidenced by the single direction from DCOILBRENTEU to specific coins. It makes sense to say that DCOILBRENTEU is an indicator of the economic situation, and so offers investors to carefully watch these indices for their movements.

Four coins (LTC, ETH, XMR, MAID) are considered the receiver from the two markets. There are some common characteristics of these coins, including: (i) a decentralization system, (ii) providing a platform for petrol-dollars in the future, and (iii) automatic 
Table 6 Renyi and Shannon transfer entropy results from DCOILWTICO to DCOILBRENTEU

\begin{tabular}{lll}
\hline Causality & $\begin{array}{l}\text { Renyi transfer } \\
\text { entropy }\end{array}$ & Shannon transfer entropy \\
\hline DCOILWTICO $\rightarrow$ & $\begin{array}{l}0.0214 * * * \\
{[0.0029]}\end{array}$ & 0.02138667 \\
DCOILBRENTEU & $\begin{array}{l}\text { DCOILWTICO } \rightarrow \\
\text { DCO.0126** }\end{array}$ & \\
DCOILBRENTEU & {$[0.0027]$} &
\end{tabular}

The symbols $*$, **, and $* * *$ denote the significance at the $10 \%, 5 \%$, and $1 \%$ levels, respectively

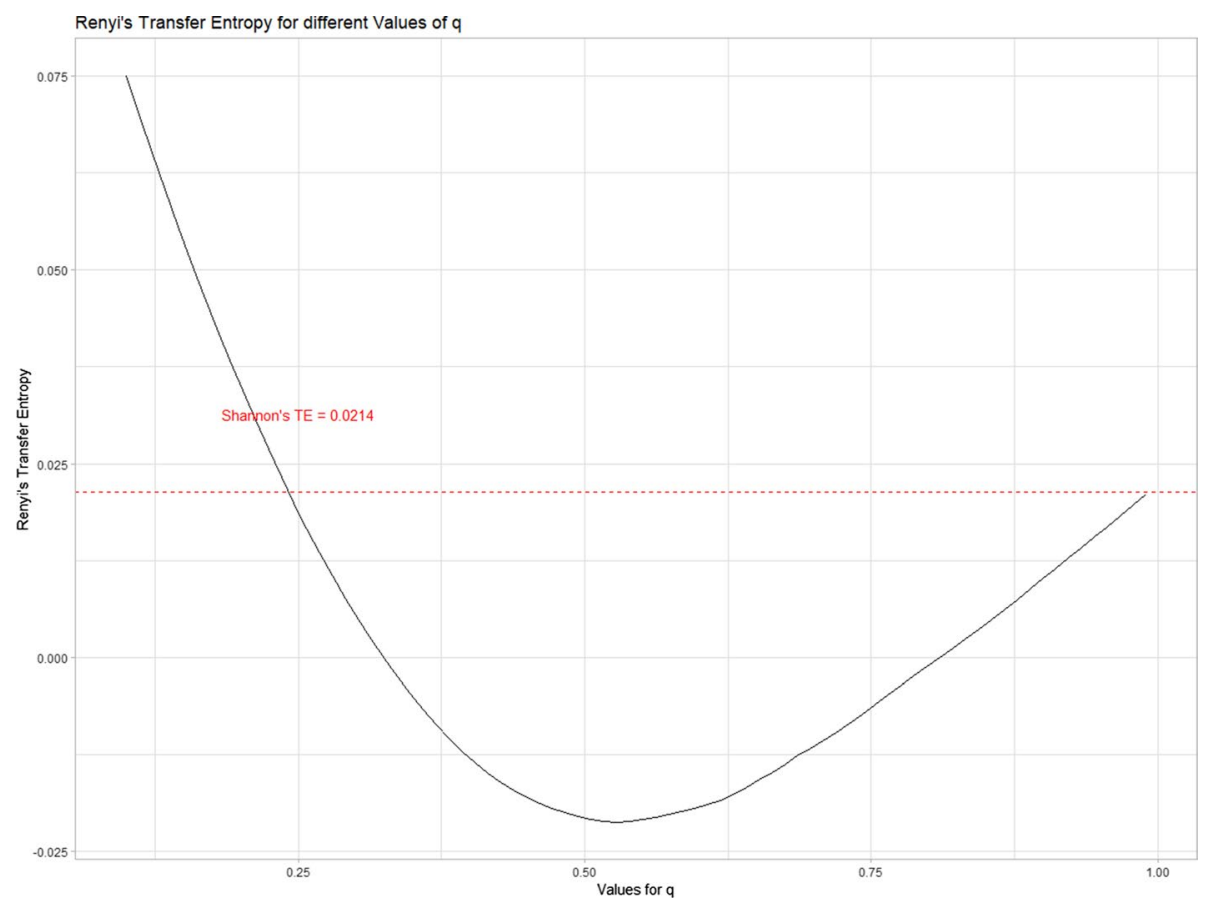

Fig. 5 Rényi transfer entropy with different values of q from the DCOILWTICO to DCOILBRENTEU

confirmation of transactions. We also observe that the process of transferring entropy from the European crude oil market to the cryptocurrency market lies in the range of $0.76 \%$ (weakest at DGB) and 1.7\% (strongest at Ethereum). Similarly, Ethereum also receives the highest transfer entropy from the US crude oil shocks. Therefore, we can conclude that Ethereum is likely to be the most passive receiver in the two crude oil markets. Concurrently, Ethereum is evaluated as the most innovative coin, as it allows many networks to be built on it, such as petrol coins or smart contracts in oil trading. Hence, there is likely to be greater information transfer from these two crude oil markets for Ethereum.

Figure 4 demonstrates the process of Rényi transfer entropy with different values of $q$ from the European crude oil market. 


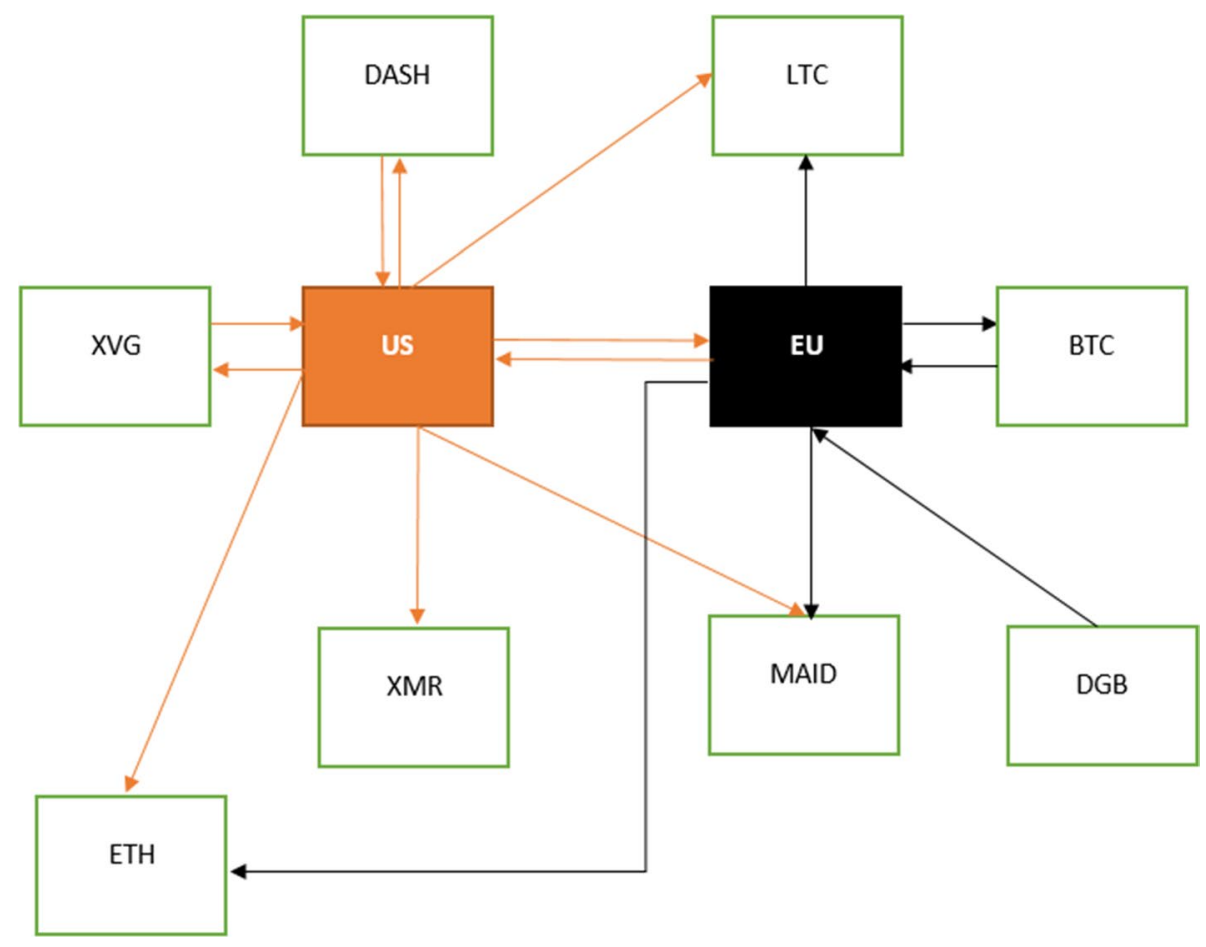

Fig. 6 The causal relationship network between the US and European Crude Oil and Cryptocurrency Markets. Note Three coins have bilateral relationships whereas the remaining coins have a unilateral relationship to a specific crude oil market. The interconnectedness between US and European crude oil markets is one of the key factors enhancing causal relationships among the cryptocurrencies

These graphs are similar to those for the transfer entropy process from the US crude oil market. At the highest q value, the transfer entropy value is lower. The highest transfer entropy values are at the lowest values of $q$.

The value of $q$ will converge to $1(q \rightarrow 1)$. In Fig. 4 , the transfer entropy value of DGB and Ethereum is highest at the smallest values of $q$ and decreases as $q$ increases. Finally, it will converge in Shannon's TE.

\subsection{The causal relationship between US and European Crude Oil Markets}

We find strong evidence of a causal relationship between the US and European crude oil prices. These results show bilateral relationships, interconnectedness and spillover effects among these markets (Table 6; Fig. 5).

The highest transfer value is at the initial quantile. The lowest value for transfer is in the median quantile. Finally, it converges into Shannon's TE at quantile $(q=1)$. This implies that the transfer entropy between the US and European crude oil markets follows a quadratic curve. This bell shape indicates that the informational shock on either the US or the European crude oil index will result in a higher risk exposure on the other oil market.

Why do we perform the causal relationship analysis between the US and European crude oil markets? We would like to deeply investigate the multidimensional effects among 
these markets to explain the mechanism for transferring entropy. By illustrating the network of causal relationships from these results, we illustrate what we achieve by employing 'Transfer Entropy' (Fig. 6).

\subsection{What we have learned from transfer entropy}

We report empirical evidence on 'Transferring entropy' process from the US and European crude oil markets to the cryptocurrency markets. We identify what particular types of coins are senders or receivers in the transmission process. Our analysis reveals that 8 of the 14 cryptocurrencies (over 50\%) have a strong connection with crude oil returns. We also find that the European crude oil market seems to be a sender whereas the US crude oil market is likely to be a receiver. This conclusion is mainly based on the bilateral relationships of the Transfer Entropy process, as it is difficult to explain how many different cryptocurrencies have casual relationships with US and European crude oil markets. Nevertheless, our findings do indicate which coins have a directional impact and the exact relationships with crude oil markets. Applying an econophysics approach such as Transferring Entropy is one of the new methodological contributions in establishing the relationships between the crude oil and cryptocurrency markets.

There are already some oil-based cryptocurrencies in the exchange markets (such as Petro for Venezuela or Neft-coin for Russia). Hence, understanding the transfer entropy process is important to explain how the co-movements of these financial assets (crude oil and cryptocurrencies) work. For instance, the shocks in crude oil markets might cause a decline in oil-based coin and depreciate the oil-cryptocurrencies issued by the government. This could be considered a contagion effect on the linked markets.

Consistent with the findings of Guesmi et al. (2018) and Symitsi and Chalvatzis (2019), our results are crucial to investigate pairs of cryptocurrencies. We also argue that it is important to study the shocks from the US and European crude oil markets, as a number of countries have indicated their intention to develop their own cryptocurrencies (using the fundamental platform of Bitcoin, Ethereum and Litecoin). Examples of these new cryptocurrencies include Bilur Energy (UK), OilCoin and PetroDollar in the USA.

It is possible to draw the conclusion that ETH is the receiver from two markets. White et al. (2020) also consider that many investors consider ETH as record transactions. In addition, ETH should be known as the oil-based characteristics to run the operations of many other cryptocurrencies. Finally, it is evident that there is no bilateral relationship between ETH and the crude oil markets. Our paper, therefore, contributes to the evidence on contagion networks as well as the precise directions from the US-European oil to cryptocurrency markets. As expected, the fundamental cryptocurrencies (such as Bitcoin, Ethereum and Litcoin) have a strong relationship with the crude oil markets. Our paper is therefore a contribution to the embryonic literature on the linkage between cryptocurrency and crude oil markets.

\subsection{Robustness check}

In order to make our results robust and consistent, we employ another methodology, namely frequency connectedness, as proposed by Baruník and Kocenda (2019), to capture the interconnectedness as well as the spillover effect for significant Transfer Entropy values in Table 4 and Table 5. However, this method is based on balanced data; thus, we have the sub-sample from 2016 to 2019 for our variables. Two main conclusions can be drawn from 
the robustness check. First, our directional frequency interconnectedness is different from zero, which indicates the presence of a causal relationship in this sub-sample using a different methodology. Second, we also see from time to time increases in the connectedness among our variables. ${ }^{7}$

\section{Conclusion and policy implications}

Fintech, smart contracts, and blockchain, cryptocurrencies are becoming one of the alternative investments. Researchers and policymakers are interested in understanding the determinants of their pricing mechanisms. Treating cryptocurrencies as another kind of monetary currency, we can observe the influence of crude oil markets on them. Cryptocurrencies are currently used as a source of innovation within the financial system, to integrate the methods of settling individual/corporate/government payments, and to anonymously transfer monetary funds. Our paper investigates the transmission channel measured by informational flows from the US and European crude oil markets to 14 different cryptocurrencies.

We found that over half of this sample of 14 cryptocurrencies are interconnected with the crude oil market (BTC (bilateral), LTC, ETH, XMR, DGB, DASH (bilateral), XVG (bilateral) and MAID). The US crude oil market is a receiver of informational flows from cryptocurrencies whereas the European crude oil is the sender in the transmission process. The features of these cryptocurrencies can be used to integrate them into a smart contract and create new coins for gasoline and crude oil trading.

Our results have important implications for investors and policymakers. First, by exploring the relationship between crude oil indices and crypto returns, investors may choose independent coins (XEM, DOGE, VTC, XLM, USDT, XRP) for their portfolios for diversification or hedging. In particular, investors can use these coins for hedging the movement of US or European crude oil movements, as their return is quite different from that of the oil indices. In other words, these coins can be added to portfolios which already contain a selection of crude oil indices. Many cryptocurrencies use digital platforms and, as a result, the trading mechanism and hedging process are likely to cost-effective and less time-consuming.

Second, for policymakers who intend to use the fundamental platform to establish petrol-coins, these findings will be very useful in understanding the dynamics and pricing mechanism of both assets. Understanding these directional movements, governments will be able to value their petrol coins and avoid the market risk or individual effects from these coins. Taking into consideration these risk factors, it is necessary for a country to use Bitcoin or Ethereum as its next-generation digital platform to build its own petrol coins, because the informational effects originating from these coins are strong.

Third, our paper adds to the theoretical literature on the economic valuation of cryptocurrencies, which is an emerging area of research in the energy literature. We apply valuation models used in Physics and contribute to the empirical evidence in establishing the transmission mechanisms of the economic value of crude oil and digital currency. Our findings thus add to the cryptocurrency puzzle and we identify alternative avenues of investments in this relatively underdeveloped area of research.

\footnotetext{
7 The results are available upon request.
} 
Fourth, the time transfer calculated in our analysis supports the evidence in the literature that the cryptocurrency market is inefficient, which gives arbitrage opportunities to investors. However, it is advisable to consider the time discrepancy in implementing the most appropriate strategies for investors. Furthermore, US policymakers can also consider the implications of European shocks to make timely decisions to restrict or minimize the spillover effects.

However, our findings are subject to limitations. Our paper could not match the automatically measured information flows from crude oil markets to cryptocurrencies. With the development of machine learning and deep learning, we can overcome this gap by using reinforcement learning with different approaches to solving this puzzle. We, however, leave this to future studies. Furthermore, our study only focuses on two of the biggest crude oil types such as WTI and BRENT while there is a potential avenue for examining the relationship between crude oil markets and cryptocurrencies in the developing economies.

We do identify avenues for future research. As cryptocurrency is an emerging line of research and we are observing inefficiency in the trading process, it will be interesting to investigate investors' choices to use one cryptocurrency rather than another. Understanding this may not be possible using traditional economics and finance models, and hence we suggest a behavioural economic perspective in understanding investors' preferences in these complex new digital markets.

\section{Appendix robustness check}

\section{WTI crude oil robustness check}

\begin{tabular}{llc}
\hline Causality & Full sample & $\begin{array}{c}\text { Frequency- } \\
\text { connected- } \\
\text { ness }\end{array}$ \\
\hline DCOILWTICO $\rightarrow$ LTC & $0.0117^{*}$ & 0.74 \\
DCOILWTICO $\rightarrow$ ETH & {$[0.0028]$} & 0.01 \\
DCOILWTICO $\rightarrow$ DASH & $0.0268^{* * *}$ & $0.0043]$ \\
& $0.0171^{* *}$ & 1.15 \\
DASH $\rightarrow$ DCOILWTICO & {$[0.0032]$} & 0.01 \\
DCOILWTICO $\rightarrow$ XMR & $0.0140^{*}$ & 0.66 \\
DCOILWTICO $\rightarrow$ XVG & {$[0.0033]$} & 13.83 \\
XVG $\rightarrow$ DCOILWTICO & $0.0136^{*}$ & \\
& {$[0.0032]$} & 7.50 \\
DCOILWTICO $\rightarrow$ MAID & $0.0132^{*}$ & 2.68 \\
& {$[0.0033]$} & \\
\hline
\end{tabular}


See Fig. 7.

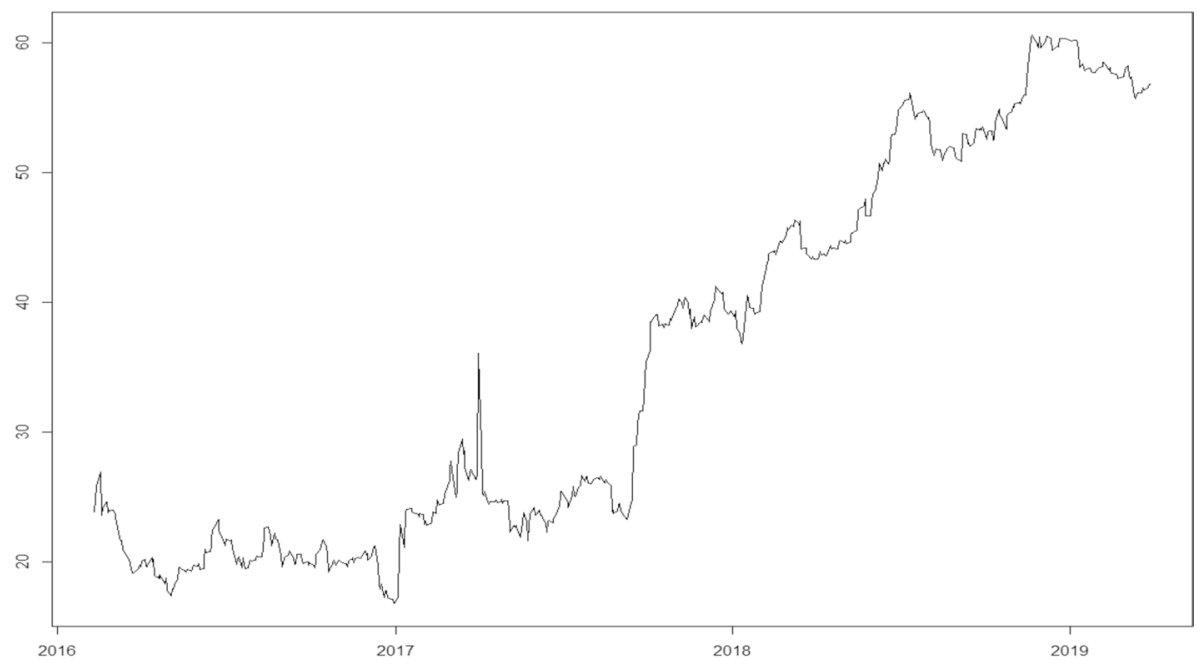

(a) WTI oil

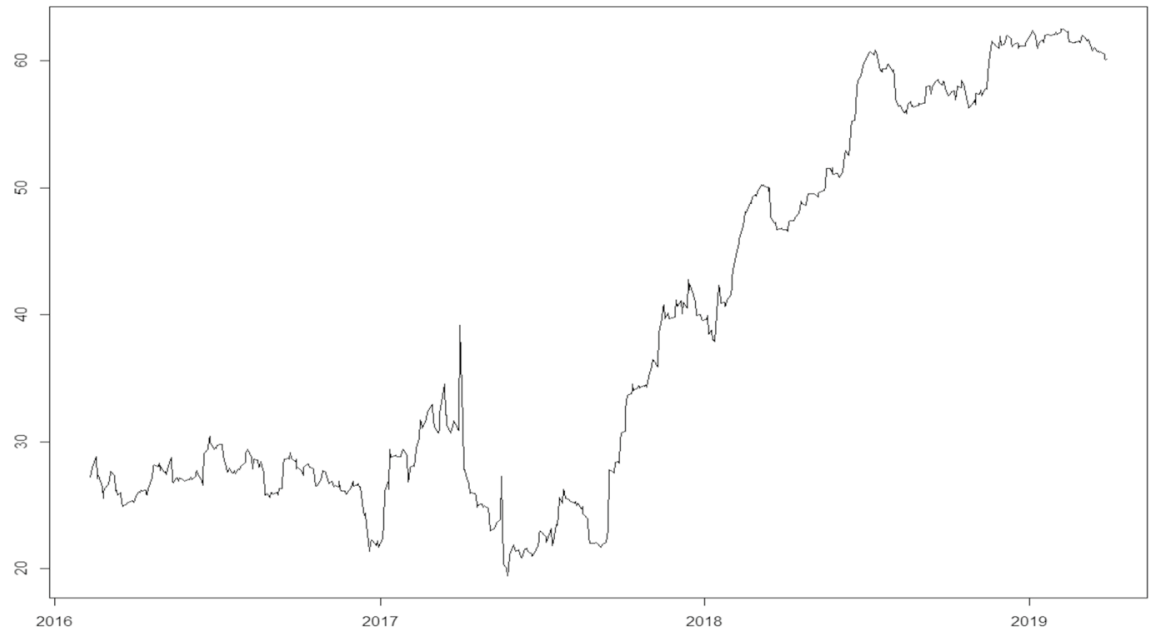

(b) BRENT oil

Fig. 7 The connectedness between cryptocurrency and crude oil markets 


\section{BRENT crude oil}

\begin{tabular}{lll}
\hline Causality & Renyi transfer entropy & $\begin{array}{l}\text { Frequency- } \\
\text { connected- } \\
\text { ness }\end{array}$ \\
\hline DCOILBRENTEU $\rightarrow$ BTC & $0.0113^{*}$ & 0.01 \\
BTC $\rightarrow$ DCOILBRENTEU & {$[0.0025]$} & 0.11 \\
& $0.0106^{*}$ & \\
DCOILBRENTEU $\rightarrow$ LTC & {$[0.0026]$} & 0.09 \\
DCOILBRENTEU $\rightarrow$ ETH & $0.0116^{*}$ & 0.16 \\
& {$[0.0028]$} & 0.11 \\
DCOILBRENTEU $\rightarrow$ XMR & $0.0177^{*}$ & 0.02 \\
DGB $\rightarrow$ DCOILBRENTEU & {$[0.0041]$} & $0.0128^{*}$ \\
DCOILBRENTEU $\rightarrow$ MAID & {$[0.0032]$} & $0.0152^{* *}$ \\
& {$[0.0031]$} & $0.0120^{*}$ \\
\hline
\end{tabular}

\section{Information on the variable's full name}

This appendix provides the insights of each cryptocurrency in terms of name, market capitalization, total supply and all time high in the exchange.

\begin{tabular}{llccl}
\hline Symbol & Name & Market capitalization (USD) & Circulating supply (unit) & Date of issue \\
\hline BTC & Bitcoin & $174,918,379,274$ & $18,236,475$ & 01st May 2013 \\
LTC & Litecoin & $4,769,521,120$ & $64,159,150$ & 01 st May 2013 \\
ETH & Ethereum & $28,589,119,108$ & $109,844,644$ & 8 th Aug 2015 \\
XEM & NEM & $21,240,638$ & $8,999,999,999$ & 3rd Apr 2015 \\
DASH & Dash & $938,226,050$ & $9,344,247$ & 15th Feb 2014 \\
DOGE & Dogecoin & $315,532,005$ & $123,461,542,248$ & 19th Dec 2013 \\
XMR & Monero & $1,398,868,850$ & $17,458,076$ & 21st May 2014 \\
VTC & Vertcoin & $16,413,384$ & $53,593,747$ & 20th Jan 2014 \\
XVG & Verge & $69,366,673$ & $16,187,838,743$ & 26th Oct 2014 \\
DGB & DigiByte & $84,789,677$ & $12,859,912,607$ & 07th Feb 2014 \\
XLM & Stellar & $1,370,120,659$ & $20,205,010,713$ & 05th Aug 2014 \\
USDT & Tether & $4,653,741,622$ & $4,642,367,414$ & 07th March 2015 \\
MAID & MaidSafeCoin & $43,986,645$ & $452,552,412$ & 28th Apr 2014 \\
XRP & Ripple & $11,642,567,056$ & $43,749,413,421$ & 07th Aug 2013 \\
\hline
\end{tabular}

Our database is updated to 25th February 2020 and retreived from coinmarketcap.com 
Funding Open Access funding enabled and organized by Projekt DEAL.

Open Access This article is licensed under a Creative Commons Attribution 4.0 International License, which permits use, sharing, adaptation, distribution and reproduction in any medium or format, as long as you give appropriate credit to the original author(s) and the source, provide a link to the Creative Commons licence, and indicate if changes were made. The images or other third party material in this article are included in the article's Creative Commons licence, unless indicated otherwise in a credit line to the material. If material is not included in the article's Creative Commons licence and your intended use is not permitted by statutory regulation or exceeds the permitted use, you will need to obtain permission directly from the copyright holder. To view a copy of this licence, visit http://creativecommons.org/licenses/by/4.0/.

\section{References}

Adler, G., \& Sosa, S. (2011). Commodity price cycles: The perils of mismanaging the boom. Washington, DC: International Monetary Fund.

Adrangi, B., Chatrath, A., Raffiee, K., \& Ripple, R. D. (2001). Alaska North Slope crude oil price and the behavior of diesel prices in California. Energy Economics, 23(1), 29-42.

Aloui, R., Aïssa, M. S. B., \& Nguyen, D. K. (2013). Conditional dependence structure between oil prices and exchange rates: A copula-GARCH approach. Journal of International Money and Finance, 32, $719-738$.

Ammous, S. (2018). The bitcoin standard: The decentralized alternative to central banking. Hoboken: Wiley.

Andersen, T. G., Bollerslev, T., \& Diebold, F. X. (2007). Roughing it up: Including jump components in the measurement, modeling, and forecasting of return volatility. The review of economics and statistics, 89(4), 701-720.

Asche, F., Gjølberg, O., \& Völker, T. (2003). Price relationships in the petroleum market: An analysis of crude oil and refined product prices. Energy Economics, 25(3), 289-301.

Atil, A., Lahiani, A., \& Nguyen, D. K. (2014). Asymmetric and nonlinear pass-through of crude oil prices to gasoline and natural gas prices. Energy Policy, 65, 567-573.

Bachmeier, L. J., \& Griffin, J. M. (2006). Testing for market integration crude oil, coal, and natural gas. The Energy Journal, 27, 55-71.

Baek, S. K., Jung, W. S., Kwon, O., \& Moon, H. T. (2005). Transfer entropy analysis of the stock market. arXiv preprint physics/0509014.

Balcilar, M., Bouri, E., Gupta, R., \& Roubaud, D. (2017). Can volume predict Bitcoin returns and volatility? A quantiles-based approach. Economic Modelling, 64, 74-81.

Balke, N. S., Brown, S. P., \& Yücel, M. K. (2002). Oil price shocks and the US economy: Where does the asymmetry originate? The Energy Journal, 23, 27-52.

Bariviera, A. F. (2017). The inefficiency of Bitcoin revisited: A dynamic approach. Economics Letters, 161, $1-4$.

Barnett, L., \& Bossomaier, T. (2012). Transfer entropy as a log-likelihood ratio. Physical Review Letters, 109(13), 138105.

Barsky, R. B., \& Kilian, L. (2004). Oil and the Macroeconomy since the 1970s. Journal of Economic Perspectives, 18(4), 115-134.

Baruník, J., \& Kocenda, E. (2019). Total, asymmetric and frequency connectedness between oil and forex markets. The Energy Journal. https://doi.org/10.5547/01956574.40.SI2.jbar.

Baur, Dirk G., Hong, Kihoon, \& Lee, Adrian D. (2018). Bitcoin: Medium of exchange or speculative assets? Journal of International Financial Markets, Institutions and Money, 54, 177-189.

Beck, C., \& Schlögl, F. (1993). Thermodynamics of chaotic systems. Cambridge: Cambridge Press.

Bekaert, G., \& Hoerova, M. (2014). The VIX, the variance premium and stock market volatility. Journal of Econometrics, 183(2), 181-192.

Blau, B. M. (2017). Price dynamics and speculative trading in bitcoin. Research in International Business and Finance, 41, 493-499.

Böhme, R., Christin, N., Edelman, B., \& Moore, T. (2015). Bitcoin: Economics, technology, and governance. Journal of Economic Perspectives, 29(2), 213-238.

Bollerslev, T., Patton, A. J., \& Quaedvlieg, R. (2016). Exploiting the errors: A simple approach for improved volatility forecasting. Journal of Econometrics, 192(1), 1-18. 
Bouri, E., Molnár, P., Azzi, G., Roubaud, D., \& Hagfors, L. I. (2017). On the hedge and safe haven properties of Bitcoin: Is it really more than a diversifier? Finance Research Letters, 20, 192-198.

Brigida, M. (2014). The switching relationship between natural gas and crude oil prices. Energy Economics, 43, 48-55.

Brown, S. P., \& Yucel, M. K. (2008). What drives natural gas prices? Energy Journal, 29(2), 45.

Chen, S. S., \& Chen, H. C. (2007). Oil prices and real exchange rates. Energy Economics, 29(3), 390-404.

Chen, K. C., Chen, S., \& Wu, L. (2009). Price causal relations between China and the world oil markets. Global Finance Journal, 20(2), 107-118.

Chuliá, H., Furió, D., \& Uribe, J. M. (2019). Volatility spillovers in energy markets. The Energy Journal, 40(3), 127-152.

Ciaian, P., \& Rajcaniova, M. (2018). Virtual relationships: Short-and long-run evidence from BitCoin and altcoin markets. Journal of International Financial Markets, Institutions and Money, 52, 173-195.

Corbet, S., Meegan, A., Larkin, C., Lucey, B., \& Yarovaya, L. (2018). Exploring the dynamic relationships between cryptocurrencies and other financial assets. Economics Letters, 165, 28-34.

Corsi, F., Pirino, D., \& Reno, R. (2010). Threshold bipower variation and the impact of jumps on volatility forecasting. Journal of Econometrics, 159(2), 276-288.

Coudert, V., \& Mignon, V. (2016). Reassessing the empirical relationship between the oil price and the dollar. Energy Policy, 95, 147-157.

Degiannakis, S. (2008). ARFIMAX and ARFIMAX-TARCH realized volatility modeling. Journal of Applied Statistics, 35(10), 1169-1180.

Degiannakis, S., \& Filis, G. (2017). Forecasting oil price realized volatility using information channels from other asset classes. Journal of International Money and Finance, 76, 28-49.

Dimpfl, T., \& Peter, F. J. (2013). Using transfer entropy to measure information flows between financial markets. Studies in Nonlinear Dynamics and Econometrics, 17(1), 85-102.

Duong, D., \& Swanson, N. R. (2015). Empirical evidence on the importance of aggregation, asymmetry, and jumps for volatility prediction. Journal of Econometrics, 187(2), 606-621.

Dyhrberg, A. H. (2016). Bitcoin, gold and the dollar-A GARCH volatility analysis. Finance Research Letters, 16, 85-92.

Elder, J., \& Serletis, A. (2010). Oil price uncertainty. Journal of Money, Credit and Banking, 42(6), 1137-1159.

Erdös, P., \& Rényi, A. (1970). On a new law of large numbers. Journal d'analyse mathématique, 23(1), 103-111.

Faes, L., Nollo, G., \& Porta, A. (2013). Compensated transfer entropy as a tool for reliably estimating information transfer in physiological time series. Entropy, 15(1), 198-219.

Furió, D., \& Chuliá, H. (2012). Price and volatility dynamics between electricity and fuel costs: Some evidence for Spain. Energy Economics, 34(6), 2058-2065.

Gajardo, G., Kristjanpoller, W. D., \& Minutolo, M. (2018). Does Bitcoin exhibit the same asymmetric multifractal cross-correlations with crude oil, gold and DJIA as the Euro, Great British Pound and Yen? Chaos, Solitons \& Fractals, 109, 195-205.

German, H., El Karoui, N., \& Rochet, J. C. (1995). Changes of numeraire, changes of probability measure and pricing of options. Journal of Applied Probability, 32, 443-458.

Giudici, P., \& Abu-Hashish, I. (2019). What determines bitcoin exchange prices? A network VAR approach. Finance Research Letters, 28, 309-318.

Giudici, P., \& Polinesi, G. (2019). Crypto price discovery through correlation networks. Annals of Operations Research. https://doi.org/10.1007/s10479-019-03282-3.

Gjolberg, O., \& Johnsen, T. (1999). Risk management in the oil industry: Can information on long-run equilibrium prices be utilized? Energy Economics, 21(6), 517-527.

Glaser, F., Zimmermann, K., Haferkorn, M., Weber, M. C., \& Siering, M. (2014). Bitcoin-asset or currency? revealing users' hidden intentions. Revealing Users’ Hidden Intentions (April 15, 2014). ECIS.

Gong, X., \& Lin, B. (2017). Forecasting the good and bad uncertainties of crude oil prices using a HAR framework. Energy Economics, 67, 315-327.

Gong, X., \& Lin, B. (2018a). Structural breaks and volatility forecasting in the copper futures market. Journal of Futures Markets, 38(3), 290-339.

Gong, X., \& Lin, B. (2018b). The incremental information content of investor fear gauge for volatility forecasting in the crude oil futures market. Energy Economics, 74, 370-386.

Granger, C. W. (1988). Causality, cointegration, and control. Journal of Economic Dynamics and Control, 12(2-3), 551-559.

Gronwald, M. (2019). Is Bitcoin a commodity? On price jumps, demand shocks, and certainty of supply. Journal of International Money and Finance, 97, 86-92. 
Guardian. (2013). NSA and GCHQ target Tor network that protects anonymity of web users. https:// www.theguardian.com/world/2013/oct/04/nsa-gchq-attack-tor-network-encryption. Retrieved 23 April, 2020.

Guesmi, K., Saadi, S., Abid, I., \& Ftiti, Z. (2018). Portfolio diversification with virtual currency: Evidence from bitcoin. International Review of Financial Analysis, 63, 431-437.

Hamilton, J. D. (2003). What is an oil shock? Journal of Econometrics, 113(2), 363-398.

Haugom, E., Langeland, H., Molnár, P., \& Westgaard, S. (2014). Forecasting volatility of the US oil market. Journal of Banking \& Finance, 47, 1-14.

Hileman, G., \& Rauchs, M. (2017). Global cryptocurrency benchmarking study. Cambridge Centre for Alternative Finance, 33, 33-113.

Hudson, R., \& Urquhart, A. (2019). Technical trading and cryptocurrencies. Annals of Operations Research. https://doi.org/10.1007/s10479-019-03357-1.

Huynh, T. L. D. (2019). Spillover risks on cryptocurrency markets: A look from VAR-SVAR granger causality and student'st copulas. Journal of Risk and Financial Management, 12(2), 1-19.

Huynh, T. L. D., Nguyen, S. P., \& Duong, D. (2018). Contagion risk measured by return among cryptocurrencies. In International econometric conference of Vietnam (pp. 987-998). Springer, Cham.

Jadidzadeh, A., \& Serletis, A. (2017). How does the US natural gas market react to demand and supply shocks in the crude oil market? Energy Economics, 63, 66-74.

Jiang, Y., Nie, H., \& Ruan, W. (2018). Time-varying long-term memory in Bitcoin market. Finance Research Letters, 25, 280-284.

Jiao, J. L., Fan, Y., Wei, Y. M., Han, Z. Y., \& Zhang, J. T. (2007). Analysis of the co-movement between Chinese and international crude oil price. International Journal of Global Energy Issues, 27(1), 61-76.

Jin, X., Lin, S. X., \& Tamvakis, M. (2012). Volatility transmission and volatility impulse response functions in crude oil markets. Energy Economics, 34(6), 2125-2134.

Jin, J., Yu, J., Hu, Y., \& Shang, Y. (2019). Which one is more informative in determining price movements of hedging assets? Evidence from Bitcoin, gold and crude oil markets. Physica A: Statistical Mechanics and its Applications, 527, 121121.

Jizba, P., Kleinert, H., \& Shefaat, M. (2012). Rényi's information transfer between financial time series. Physica A: Statistical Mechanics and its Applications, 391(10), 2971-2989.

Jo, S. (2014). The effects of oil price uncertainty on global real economic activity. Journal of Money, Credit and Banking, 46(6), 1113-1135.

Kaiser, L. (2018). Seasonality in cryptocurrencies. Finance Research Letters. https://doi.org/10.1016/j.frl. 2018.11.007.

Kallinterakis, V. (2019). Do investors herd in cryptocurrencies-And why? Research in International Business and Finance. https://doi.org/10.1016/j.ribaf.2019.05.005.

Katsiampa, P. (2017). Volatility estimation for Bitcoin: A comparison of GARCH models. Economics Letters, 158, 3-6.

Keynes, J. M. (1923). Some aspects of commodity markets. Manchester Guardian Commercial: European Reconstruction Series, 13, 784-786.

Kilian, L., \& Park, C. (2009). The impact of oil price shocks on the US stock market. International Economic Review, 50(4), 1267-1287.

Kim, J., Kim, G., An, S., Kwon, Y. K., \& Yoon, S. (2013). Entropy-based analysis and bioinformaticsinspired integration of global economic information transfer. PLOS ONE, 8(1), e51986.

Koutmos, D. (2018). Return and volatility spillovers among cryptocurrencies. Economics Letters, 173, 122-127.

Koutmos, D. (2019). Market risk and Bitcoin returns. Annals of Operations Research. https://doi.org/10. 1007/s10479-019-03255-6.

Krugman, P. (1983). Oil shocks and exchange rate dynamics. In Exchange rates and international macroeconomics (pp. 259-284). University of Chicago Press.

Kullback, S., \& Leibler, R. A. (1951). On information and sufficiency. The Annals of Mathematical Statistics, 22(1), 79-86.

Kunkler, M., \& MacDonald, R. (2019). The multilateral relationship between oil and G10 currencies. Energy Economics, 78, 444-453.

Kwon, O., \& Yang, J. S. (2008). Information flow between stock indices. EPL (Europhysics Letters), 82(6), 68003.

Laherrere, J. (2006). Oil and gas: What future? World, 1(292,549), 534.

Lanza, A., Manera, M., \& Giovannini, M. (2005). Modeling and forecasting cointegrated relationships among heavy oil and product prices. Energy Economics, 27(6), 831-848. 
Li, J., Liang, C., Zhu, X., Sun, X., \& Wu, D. (2013). Risk contagion in Chinese banking industry: A transfer entropy-based analysis. Entropy, 15(12), 5549-5564.

Lin, S. X., \& Tamvakis, M. N. (2001). Spillover effects in energy futures markets. Energy Economics, 23(1), 43-56.

Liu, W. (2018). Portfolio diversification across cryptocurrencies. Finance Research Letters. https://doi.org/ 10.1016/j.frl.2018.07.010.

Liu, T., \& Gong, X. (2020). Analyzing time-varying volatility spillovers between the crude oil markets using a new method. Energy Economics, 87, 104711.

Liu, L., Hu, H., Deng, Y., \& Ding, N. (2014). An entropy measure of non-stationary processes. Entropy, 16(3), 1493-1500.

Liu, Q., \& Tu, A. H. (2012). Jump spillovers in energy futures markets: Implications for diversification benefits. Energy Economics, 34(5), 1447-1464.

Liu, J., Wei, Y., Ma, F., \& Wahab, M. I. M. (2017). Forecasting the realized range-based volatility using dynamic model averaging approach. Economic Modelling, 61, 12-26.

Lizardo, R. A., \& Mollick, A. V. (2010). Oil price fluctuations and US dollar exchange rates. Energy Economics, 32(2), 399-408.

Lizier, J., \& Mahoney, J. (2013). Moving frames of reference, relativity and invariance in transfer entropy and information dynamics. Entropy, 15(1), 177-197.

Lizier, J. T., Prokopenko, M., \& Zomaya, A. Y. (2008). Local information transfer as a spatiotemporal filter for complex systems. Physical Review E, 77(2), 026110.

Ma, Y. R., Ji, Q., \& Pan, J. (2019). Oil financialization and volatility forecast: Evidence from multidimensional predictors. Journal of Forecasting, 38(6), 564-581.

Ma, F., Liu, J., Huang, D., \& Chen, W. (2017). Forecasting the oil futures price volatility: A new approach. Economic Modelling, 64, 560-566.

Marschinski, R., \& Kantz, H. (2002). Analysing the information flow between financial time series. The European Physical Journal B-Condensed Matter and Complex Systems, 30(2), 275-281.

Miller, M. H., \& Scholes, M. (1972). Rates of return in relation to risk: A reexamination of some recent findings. Studies in the Theory of Capital Markets, 23, 47-48.

Nadarajah, S., \& Chu, J. (2017). On the inefficiency of Bitcoin. Economics Letters, 150, 6-9.

Nasir, M. A., Huynh, T. L. D., \& Tram, H. T. X. (2019). Role of financial development, economic growth \& foreign direct investment in driving climate change: A case of emerging ASEAN. Journal of Environmental Management, 242, 131-141.

Peng, Y., Albuquerque, P. H. M., de Sá, J. M. C., Padula, A. J. A., \& Montenegro, M. R. (2018). The best of two worlds: Forecasting high frequency volatility for cryptocurrencies and traditional currencies with support vector regression. Expert Systems with Applications, 97, 177-192.

Peter, F. J., Dimpfl, T., \& Huergo, L. (2011). Using transfer entropy to measure information flows from and to the CDS market. In Midwest Finance Association 2012 annual meetings paper. http://ssrn. com/abstract (Vol. 1683948). Accessed 30 Sept 2019.

Phan, D. H. B., Sharma, S. S., \& Narayan, P. K. (2016). Intraday volatility interaction between the crude oil and equity markets. Journal of International Financial Markets, Institutions and Money, 40, $1-13$.

Pieters, G., \& Vivanco, S. (2017). Financial regulations and price inconsistencies across Bitcoin markets. Information Economics and Policy, 39, 1-14.

Pindyck, R. S. (2003). Volatility in natural gas and oil markets. Journal of Energy and Development, $30(1), 1-19$.

Prokopczuk, M., Symeonidis, L., \& Wese Simen, C. (2016). Do jumps matter for volatility forecasting? Evidence from energy markets. Journal of Futures Markets, 36(8), 758-792.

Prokopenko, M., Lizier, J., \& Price, D. (2013). On thermodynamic interpretation of transfer entropy. Entropy, 15(2), 524-543.

Ramberg, D. J., \& Parsons, J. E. (2010). The weak tie between natural gas and oil prices. Center for Energy and Environmental Policy Research (CEEPR) No, 10-017.

Raymaekers, W. (2015). Cryptocurrency Bitcoin: Disruption, challenges and opportunities. Journal of Payments Strategy \& Systems, 9(1), 30-46.

Reboredo, J. C. (2012). Modelling oil price and exchange rate co-movements. Journal of Policy Modeling, 34(3), 419-440.

Reboredo, J. C., Rivera-Castro, M. A., \& Zebende, G. F. (2014). Oil and US dollar exchange rate dependence: A detrended cross-correlation approach. Energy Economics, 42, 132-139.

Sadorsky, P. (2012). Correlations and volatility spillovers between oil prices and the stock prices of clean energy and technology companies. Energy Economics, 34(1), 248-255.

Schreiber, T. (2000). Measuring information transfer. Physical Review Letters, 85(2), 461. 
Selmi, R., Mensi, W., Hammoudeh, S., \& Bouoiyour, J. (2018). Is Bitcoin a hedge, a safe haven or a diversifier for oil price movements? A comparison with gold. Energy Economics, 74, 787-801.

Sensoy, A. (2019). The inefficiency of Bitcoin revisited: A high-frequency analysis with alternative currencies. Finance Research Letters, 28, 68-73.

Serletis, A. (1994). A cointegration analysis of petroleum futures prices. Energy Economics, 16(2), 93-97.

Serletis, A., \& Rangel-Ruiz, R. (2004). Testing for common features in North American energy markets. Energy Economics, 26(3), 401-414.

Sévi, B. (2014). Forecasting the volatility of crude oil futures using intraday data. European Journal of Operational Research, 235(3), 643-659.

Shahbaz, M., Nasir, M. A., \& Roubaud, D. (2018). Environmental degradation in France: The effects of FDI, financial development, and energy innovations. Energy Economics, 74, 843-857.

Shannon, C. E. (1948). A mathematical theory of communication. Bell System Technical Journal, 27(3), 379-423.

Stokes, R. (2012). Virtual money laundering: the case of Bitcoin and the Linden dollar. Information \& Communications Technology Law, 21(3), 221-236.

Sumioka, H., Yoshikawa, Y., \& Asada, M. (2007). Causality detected by transfer entropy leads acquisition of joint attention. In 2007 IEEE 6th international conference on development and learning (pp. 264-269). IEEE.

Symitsi, E., \& Chalvatzis, K. J. (2018). Return, volatility and shock spillovers of Bitcoin with energy and technology companies. Economics Letters, 170, 127-130.

Symitsi, E., \& Chalvatzis, K. J. (2019). The economic value of Bitcoin: A portfolio analysis of currencies, gold, oil and stocks. Research in International Business and Finance, 48, 97-110.

Tian, F., Yang, K., \& Chen, L. (2017). Realized volatility forecasting of agricultural commodity futures using the HAR model with time-varying sparsity. International Journal of Forecasting, 33(1), 132-152.

Urquhart, A. (2016). The inefficiency of Bitcoin. Economics Letters, 148, 80-82.

Van Wijk, D. (2013). What can be expected from the BitCoin. Rotterdam: Erasmus Universiteit Rotterdam.

Vandezande, N. (2017). Virtual currencies under EU anti-money laundering law. Computer Law \& Security Review, 33(3), 341-353.

Ver Steeg, G., \& Galstyan, A. (2012). Information transfer in social media. In Proceedings of the 21st international conference on World Wide Web (pp. 509-518). ACM.

Wang, Y., Ma, F., Wei, Y., \& Wu, C. (2016a). Forecasting realized volatility in a changing world: A dynamic model averaging approach. Journal of Banking \& Finance, 64, 136-149.

Wang, J., Xue, Y., \& Liu, M. (2016a). An analysis of bitcoin price based on VEC model. In 2016 international conference on economics and management innovations. Atlantis Press.

Wen, F., Gong, X., \& Cai, S. (2016). Forecasting the volatility of crude oil futures using HAR-type models with structural breaks. Energy Economics, 59, 400-413.

White, R., Marinakis, Y., Islam, N., \& Walsh, S. (2020). Is Bitcoin a currency, a technology-based product, or something else? Technological Forecasting and Social Change, 151, 119877.

Yermack, D. (2015). Is Bitcoin a real currency? An economic appraisal. In D. Lee Kuo Chuen and S. Kee Boon (Eds), Handbook of digital currency (pp. 31-43). Academic Press.

Zamani, N. (2016). How the crude oil market affects the natural gas market? Demand and supply shocks. International Journal of Energy Economics and Policy, 6(2), 217-221.

Publisher's Note Springer Nature remains neutral with regard to jurisdictional claims in published maps and institutional affiliations. 